\title{
Predicting Indoor Temperature Distribution Based on Contribution Ratio of Indoor Climate (CRI) and Mobile Sensors
}

\author{
Yanan Zhao ${ }^{1} \mathbb{D}$, Zihan Zang ${ }^{1}$, Weirong Zhang ${ }^{1, *}$, Shen Wei ${ }^{2} \mathbb{D}$ and Yingli Xuan ${ }^{3}$ \\ 1 Key Laboratory of Green Built Environment and Energy Efficient Technology, Beijing University of \\ Technology, Beijing 100022, China; zhaoyn@emails.bjut.edu.cn (Y.Z.); CML9817@emails.bjut.edu.cn (Z.Z.) \\ 2 The Bartlett School of Construction and Project Management, University College London (UCL), \\ 1-19 Torrington Place, London WC1E 7HB, UK; shen.wei@ucl.ac.uk \\ 3 Joint Usage/Research Center Wind Engineering Research Center Tokyo Polytechnic University, \\ Tokyo Polytechnic University, Tokyo 164-8678, Japan; y.xuan@arch.t-kougei.ac.jp \\ * Correspondence: zhangwr@bjut.edu.cn
}

Citation: Zhao, Y.; Zang, Z. Zhang, W.; Wei, S.; Xuan, Y. Predicting Indoor Temperature Distribution Based on Contribution Ratio of Indoor Climate (CRI) and Mobile Sensors. Buildings 2021, 11, 458 .

https://doi.org/buildings11100458

Academic Editor: Fabrizio Ascione

Received: 28 July 2021

Accepted: 28 September 2021

Published: 4 October 2021

Publisher's Note: MDPI stays neutral with regard to jurisdictional claims in published maps and institutional affiliations.

Copyright: (c) 2021 by the authors. Licensee MDPI, Basel, Switzerland. This article is an open access article distributed under the terms and conditions of the Creative Commons Attribution (CC BY) license (https:// creativecommons.org/licenses/by/ $4.0 /)$

\begin{abstract}
In practical building control, quickly obtaining detailed indoor temperature distribution is necessary for providing satisfying personal comfort and improving building energy efficiency. The aim of this study is to propose a fast prediction method for indoor temperature distribution without knowing the thermal boundary conditions in practical applications. In this method, the index of contribution ratio of indoor climate (CRI), which represents the independent contribution of each heat source to the temperature distribution, has been combined with the air temperature collected by one mobile sensor at the height of the working area. Based on a typical office model, the effectiveness of using mobile sensors was discussed, and the influence of its acquisition height and acquisition distance on the prediction accuracy was analyzed as well. The results showed that the proposed prediction method was effective. When the sensors fixed on the wall were used to predict the indoor temperature distribution, the maximum average relative error was $27.7 \%$, whereas when the mobile sensor was used to replace the fixed sensors, the maximum average relative error was $4.8 \%$. This indicates that using mobile sensors with flexible acquisition location can help promote both reliability and accuracy of temperature prediction. In the human activity area, data from a set of mobile sensors were used to predict the temperature distribution at four heights. The prediction accuracy was $2.1 \%, 2.1 \%, 2.3 \%$, and $2.7 \%$, respectively. However, the influence of acquisition distance of mobile sensors on prediction accuracy cannot be ignored. The distance should be large enough to disperse the distribution of the acquisition points. Due to the influence of airflow, some distance between the acquisition points and the room boundaries should be given.
\end{abstract}

Keywords: temperature distribution; prediction; CFD; contribution ratio of indoor climate (CRI); mobile sensors

\section{Introduction}

As people spend about $90 \%$ of their time indoors [1], the indoor thermal environment becomes very important to their daily lives. Therefore, many researchers have made considerable efforts in creating comfortable indoor thermal environments to improve people's living conditions [2,3]. Meanwhile, the indoor thermal environment also has a significant impact on buildings' energy consumption, which is very important for sustainable development. Existing studies have shown that the energy consumption from buildings in China accounts for approximately $21 \%$ of the societal energy consumption, especially from urban buildings (75\%) [4]. To reduce the energy consumption of buildings while ensuring thermal comfort, creating non-uniform indoor thermal environments has been considered. In this process, the buildings' ventilation mode gradually changes from traditional mixed ventilation (MV) to demand-oriented ventilation, such as displacement ventilation (DV) $[5,6]$ and stratum ventilation (SV) $[7,8]$. The change of ventilation mode means that 
the indoor thermal environment cannot be considered as perfectly mixed, and obtaining its detailed temperature distribution becomes necessary. Computational fluid dynamics (CFD) has been used as an effective tool for studies of indoor thermal environments, such as airflow movement $[9,10]$, heat transfer between indoor components [11,12] and pollutant dispersion $[13,14]$. Indoor temperature distribution, however, is affected by various heat sources, which are dynamically changing with time, hence difficult to obtain in practice. This means that accurate boundary conditions could not be identified in advance to support CFD simulation. Additionally, the requirements on both computational resources and time for CFD are high. Even if the required dynamic boundary conditions can be determined in advance, for example by supercomputers, the process still must set and calculate CFD repeatedly to achieve dynamic calculation of the indoor thermal environment, which is time-consuming. Considering the above, it is difficult to achieve real-time control of indoor thermal environments by this method.

In this regard, several new methods have been proposed to replace CFD for quick calculation of indoor temperature distribution. The CFD reduced-order method achieves the reduction of the order of large-scale simultaneous equations in CFD, using grid number as dimensions, and it can effectively increase the calculation efficiency with some sacrifice in accuracy. Sempey et al. simplified the CFD model by solving only the energy balance equation and reducing its order by proper orthogonal decomposition so that it can be applied to real-time control applications [15]. To improve the problems of CPU-unfriendly calculations as well as the complex meshing required, Cao et al. proposed applying the momentum source to the Navier-Stokes equations to simulate the motion of human bodiess/objects [16]. Fast fluid dynamics (FFD) is an intermediate approach between nodal models and CFD, which decouples pressure and velocity to achieve fast prediction of indoor airflow $[17,18]$. When integrating the models for HVAC systems with coupled multizone and CFD simulations for airflows, Tian et al. have incorporated the FFD model to improve computational efficiency [19]. Liu et al. have proposed an FFD-based joint method to accelerate the indoor-environment inverse design process and evaluated the effectiveness of four FFD models [20]. Contribution ratio of indoor climate (CRI) is an index extracted from CFD calculation results, and it quantitatively represents the independent contribution of each heat source on indoor temperature distribution. This index was first proposed by Kato et al. in 1994 [21], and it was derived from Sandberg's ventilation efficiency [22] and Kato's effectiveness of contamination exhaust [23]. Zhang et al. have extended both the concept and the calculation method of CRI to the natural convection airflow field [24]. Based on this, they further proposed a basic formula for calculating the temperature distribution and combined it with network models to improve the accuracy of long-term dynamic building performance simulation [25]. The accessibility, which is similar in concept to CRI, describes the independent effect of supply air and contaminant source on an arbitrary location within a finite time period [26]. Shao et al. have proposed a concise expression for fast prediction of indoor non-uniform temperature distribution using the accessibility and analyzed its reliability [27]. Additionally, Ma et al. further defined three transient accessibility indices to reveal the transient effects of supply air, contaminant source, and initial condition, respectively, and established a method predicting the concentration distribution in transient states [28]. The low-dimensional model (LM) uses the discrete method to greatly reduce the amount of high-resolution grid data in order to save computational time [29]. To verify its reliability [30], Ren and Cao elaborated the linear temperature model (LTM) to attain an LLTM (low-dimensional linear temperature model)-based CRI model for fast and reliable calculation of complicated temperature fields [31]. Although the methods noted above can accelerate the calculation of indoor temperature distribution to a certain extent, they still need significant calculation time in practical applications. For instance, although it has been reported that the calculation speed of FFD is 20-50 times faster than that of CFD simulation [32] and could potentially be accelerated with a graphic processing unit (GPU) and parallel computation [33,34], its calculation time is still much longer than that is required by BES. More importantly, 
these methods were all derived from CFD itself, so the requirement to have pre-determined indoor heat sources still exists, hence they are still difficult to use in practical applications.

To develop a temperature distribution prediction method suitable for practical control, Sasamoto et al. have developed a method that can quickly predict indoor temperature distribution using CRI and a finite number of air temperature measurements collected by fixed sensors [35]. However, due to the limitation of the fixed sensors in both installation location and installation number, its prediction accuracy needs to be improved. Therefore, this study has proposed to use one mobile sensor at the height of working areas, instead of fixed sensors, to collect air temperature, with the intention to get faster and more accurate prediction of temperature distribution. Through establishing a typical office model, the effectiveness of using mobile sensors instead of fixed sensors was explored and discussed. Meanwhile, through a comparison on prediction accuracy, the influences of both acquisition height and acquisition distance of this mobile sensor were further analyzed to guide practical applications.

\section{Method Development}

\subsection{Definition of CRI}

Based on an assumption that heat transfer is linear in a steady airflow field, the CRI index can be used to represent the independent contribution of each heat source to indoor temperature distribution. This concept has been extended to the response factor of heat sources in transient cases $[36,37]$ and the evaluation of contaminant and moisture distribution [23,38]. Its specific definition in a forced convection airflow field is the ratio of temperature rise/drop at a location caused by one individual heat source to the absolute value of uniform temperature rise/drop caused by the same heat source. It indicates the range and degree of influence from each heat source within a steady airflow field, and its value is a relative intensity, in which the actual temperature rise/drop caused by each heat source is normalized by the absolute value of its own perfect mixing condition. For example, a CRI higher/lower than 1.0 at a location means that the influence of that heat source is higher/lower than that in the case of perfect mixing. The CRI of the heat source $i$ at the location $X_{j}$ is defined by Equation (1):

$$
C R I_{i}\left(X_{j}\right)=\frac{\Delta \theta_{i}\left(X_{j}\right)}{\Delta \theta_{i, o}}=\frac{\theta_{i}\left(X_{j}\right)-\theta_{n}}{\theta_{i, o}-\theta_{n}}=\frac{\theta_{i}\left(X_{j}\right)-\theta_{n}}{q_{i} / C_{p} \rho F}
$$

In one example, the heat emission from the heat source $i$ is $200 \mathrm{~W}$, resulting in a temperature rise of $0.8^{\circ} \mathrm{C}$ at the location $X_{j}$. If heat diffuses uniformly through the whole space, the uniform temperature rise will be $1^{\circ} \mathrm{C}$. According to Equation (1), the CRI of the heat source $i$ at the location $X_{j}$ is 0.8 , indicating that the heat source $i$ has a smaller impact than the average indoor environment at the location $X_{j}$.

For more information about the basic premises, definitions, calculation methods, and mathematical meaning of CRI, please refer to Zhang et al., which gives a systematic and comprehensive introduction of this term [39].

\subsection{Prediction Algorithm}

As the airflow field can be considered as stable, the CRI of each heat source can be seen as constant. This means that if the heat emission or absorption from one heat source increases by a factor of 3, the temperature rise/drop within the field will increase by a factor of 3, regardless of location. Therefore, the CRI is an effective index for calculating dynamic temperature distribution without repeating CFD calculations. That is, when the heat emission or absorption from any heat source changes, the temperature change caused by this heat source at any location could be calculated by multiplying the heat by its CRI. A new temperature distribution can then be obtained by superimposing the effect of all heat sources. Therefore, when there are $m$ heat sources in a room dominated by forced convection, the temperature rise/drop could be defined as $\Delta \theta_{i, o}$ and the CRI of heat source $i$ to the location $j$ as $C_{j i}$, when the heat emission or absorption from each heat 
source uniformly diffuses throughout the entire room. The temperature rise/drop from the neutral temperature at any location $\Delta \theta\left(X_{j}\right)$ could then be expressed by Equation (2):

$$
\Delta \theta\left(X_{j}\right)=C_{j 1} \cdot \Delta \theta_{1, o}+C_{j 2} \cdot \Delta \theta_{2, o}+\ldots+C_{j m} \cdot \Delta \theta_{m, o}
$$

Generally, the $m$ heat sources include not only directly convective heat sources but also radiative heat sources, like walls. These radiative heat sources may not generate heat themselves, but they gain heat from other heat sources by radiation and then transfer heat to or absorb heat from indoor air by convection. Therefore, both directly convective heat source sand radiative heat sources were considered as contributing to the temperature distribution. For accurate prediction of temperature at any location, all CRI and the uniform temperature rise/drop caused by them need to be calculated.

By rewriting Equation (2) into matrix form, Equation (3) is obtained:

$$
\Delta \theta\left(X_{j}\right)=\left[\begin{array}{llll}
C_{j 1} & C_{j 2} & \cdots & C_{j m}
\end{array}\right]\left[\begin{array}{c}
\Delta \theta_{1, o} \\
\Delta \theta_{2, o} \\
\vdots \\
\Delta \theta_{m, o}
\end{array}\right]
$$

In practice, the thermal boundary conditions of indoor thermal environments are generally dynamic and difficult to determine. Even if only steady-state calculations areconsidered, the intensity of each heat source still cannot be determined accurately. That is, the uniform temperature rise/drop caused by all heat sources cannot be determined accurately. Therefore, when calculating the uniform temperature rise/drop caused by each heat source, one mobile sensor was used to collect air temperature at $n$ arbitrary locations in space (defined as $\Delta \theta_{s i}$ ) and the measured temperature was then substituted into Equation (3), as shown in Equation (4):

$$
\left[\begin{array}{c}
\Delta \theta_{s 1}^{\prime} \\
\Delta \theta_{s 2}^{\prime} \\
\vdots \\
\Delta \theta_{s n}^{\prime}
\end{array}\right]=\left[\begin{array}{cccc}
C_{11} & C_{12} & \cdots & C_{1 m} \\
C_{21} & C_{22} & \cdots & C_{2 m} \\
\vdots & \vdots & \ddots & \vdots \\
C_{1 m} & C_{2 m} & \cdots & C_{n m}
\end{array}\right]\left[\begin{array}{c}
\Delta \theta_{1,0} \\
\Delta \theta_{2, o} \\
\vdots \\
\Delta \theta_{m, o}
\end{array}\right]
$$

According to Equation (4), in order to calculate $\Delta \theta_{i, o}$, it needs to multiply the inverse matrix $C_{i j}$ on both sides of the equation. This requires that the number of air temperature measurements collected within a space should be equal to the number of heat sources, that is, $n=m$. The $\Delta \theta_{i, o}$ could then be obtained by Equation (5):

$$
\left[\begin{array}{c}
\Delta \theta_{1, o} \\
\Delta \theta_{2,0} \\
\vdots \\
\Delta \theta_{m, o}
\end{array}\right]=\left[\begin{array}{cccc}
C_{11} & C_{12} & \cdots & C_{1 m} \\
C_{21} & C_{22} & \cdots & C_{2 m} \\
\vdots & \vdots & \ddots & \vdots \\
C_{1 m} & C_{2 m} & \cdots & C_{m m}
\end{array}\right]^{-1}\left[\begin{array}{c}
\Delta \theta_{s 1}^{\prime} \\
\Delta \theta_{s 2}^{\prime} \\
\vdots \\
\Delta \theta_{s n}^{\prime}
\end{array}\right]
$$

By substituting Equation (5) into Equation (3), an expression for predicting temperature at any location can be obtained, as defined by Equation (6):

$$
\Delta \theta\left(X_{j}\right)=\left[\begin{array}{llll}
C_{j 1} & C_{j 2} & \cdots & C_{j m}
\end{array}\right]\left[\begin{array}{cccc}
C_{11} & C_{12} & \cdots & C_{1 m} \\
C_{21} & C_{22} & \cdots & C_{2 m} \\
\vdots & \vdots & \ddots & \vdots \\
C_{1 m} & C_{2 m} & \cdots & C_{m m}
\end{array}\right]^{-1}\left[\begin{array}{c}
\Delta \theta_{s 1}^{\prime} \\
\Delta \theta_{s 2}^{\prime} \\
\vdots \\
\Delta \theta_{s n}^{\prime}
\end{array}\right]
$$

According to Equation (6), the temperature distribution can be predicted through calculating the CRI of each heat source in advance and collecting air temperature measurements equal to the number of heat sources. 


\subsection{Mobile Sensors}

As noted earlier, Sasamoto et al. used some fixed sensors equal to the number of heat sources to collect air temperature measurements in a space and then combined them with CRI for temperature distribution prediction [35]. This method is suitable for practical applications without identified boundary conditions in advance. However, there are limitations in terms of both installation locations and installation numbers. For example, when the number of monitored data points increases, the number of fixed sensors also needs to increase, leading to higher expense and bigger installation space needs. Additionally, the installation locations of fixed sensors are not changeable and are usually far away from the target control area, such as near air outlets, at high positions on the wall, or where people cannot easily touch them. This means that the air temperature collected for Equation (6) is location-dependent, so it may not be representative of the real situation of each heat source.

With the development of mobile carriers in control engineering, mobile sensor technology has become a popular solution for controlling buildings' indoor environment, to overcome the limitations of fixed sensors. Xue and Zhai have developed a method using mobile sensors to capture both spatial and temporal distributions of pollutant concentrations in order to estimate the location of pollutant sources [40]. This method does not consider thermal factors, especially the influence of a change in the heat source on the airflow field, and it also adopts the probability method to explore the most probable location of pollutant sources, so it cannot achieve simple calculation of temperature at any location within a space. However, using mobile sensors to monitor environmental information provides a feasible and efficient idea for studies of indoor thermal environments.

Therefore, in this study, one mobile sensor (as shown in Figure 1) has been used to replace fixed sensors when collecting air temperatures within a space. Mobile sensors have the characteristics of variable acquisition height, diverse acquisition path, and flexible acquisition location. They are adjustable according to actual requirements or prediction demand to collect more suitable data with no restrictions, to achieve better temperature distribution prediction by Equation (6).

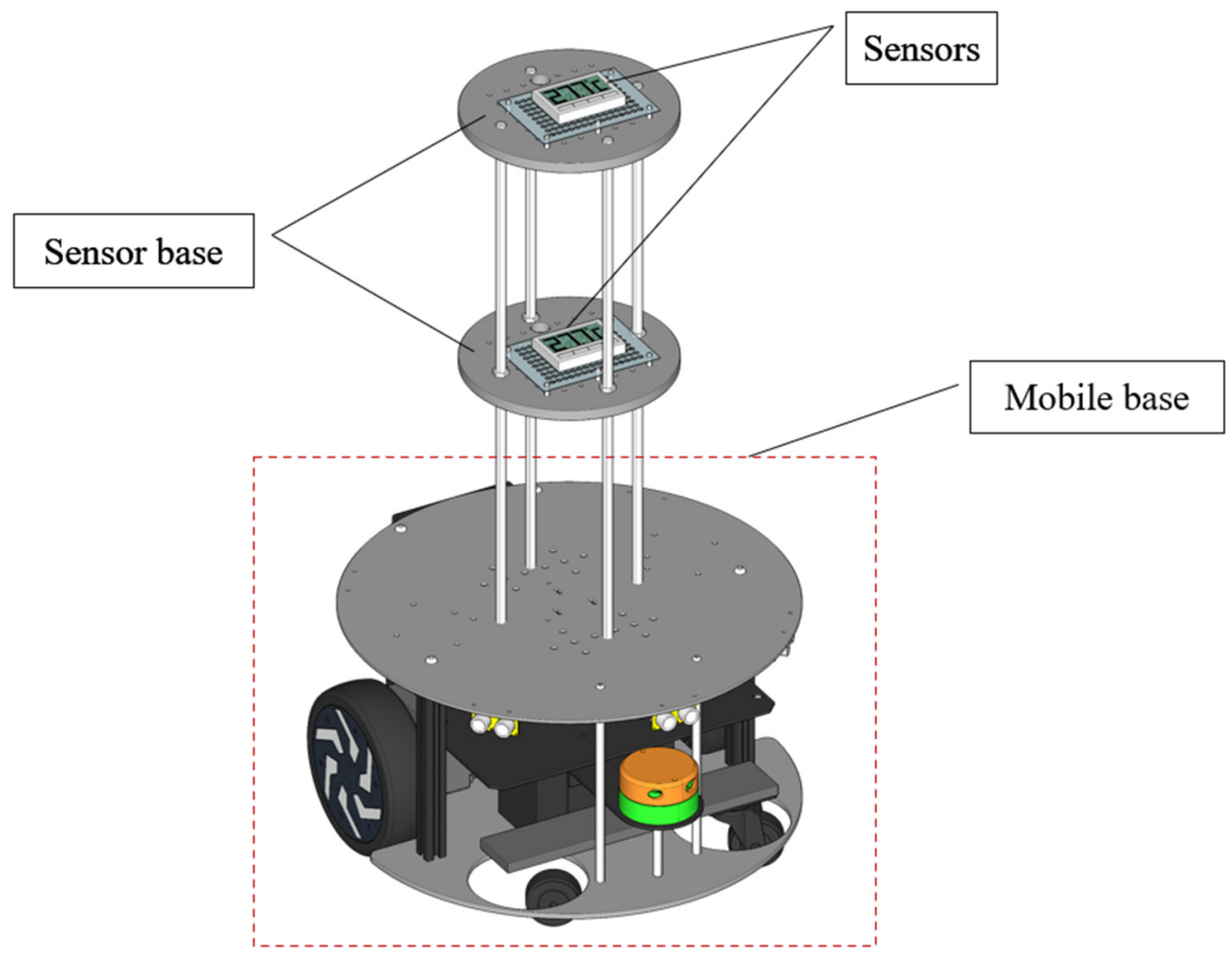

Figure 1. A mobile sensor. 


\section{Case Study}

\subsection{Verification of CFD Simulation}

In this study, both indoor airflow field and temperature field were simulated using Ansys Fluent-a CFD tool that accounts for both indoor airflow and temperature distribution characteristics. The finite volume method was used to discretize the Reynolds averaged Navier-Stokes equations and the averaged energy and mass conservation equations. The standard $k-\varepsilon$ model and the discrete ordinates (DO) model were used to simulate both indoor turbulent flow and indoor radiation. The air materials adopted the Boussinesq model to consider the buoyancy term, which treats air density as a constant value in all solved equations, except for the buoyancy term in the momentum equation. The SIMPLE algorithm was adopted to solve the pressure-velocity coupling problem, and the standard scheme was applied for pressure discretization. The second-order upwind difference scheme was used for momentum and energy. A linear under-relaxation iteration was used to ensure convergence. The energy and other solutions were converged until the residuals of all cells in the simulation domain reached within $10^{-8}$ and $10^{-4}$.

To validate the accuracy of simulation from ANSYS Fluent, a full-scale model was established and its prediction results were compared with data collected from the experiment done by Tian et al. [41], with a test chamber of $4.0 \mathrm{~m}$ (length) $\times 3.5 \mathrm{~m}$ (width) $\times 3.5 \mathrm{~m}$ (height), as shown in Figure 2, with thermally insulated walls, floor, and ceiling. There was a desk, a closet, a computer, and a thermal manikin in the test chamber, with three fluorescents installed on the ceiling. The manikin and the three fluorescents led to a total cooling load of $496 \mathrm{~W}$, thus about $35 \mathrm{~W} / \mathrm{m}^{2}$. After a grid-independence test, 643,585 grids were adopted to balance accuracy and time. The air was supplied from a double grille diffuser located at the height of $1.36 \mathrm{~m}$ above the floor while the air was exhausted through a left-wall-based diffuser mounted at the height of $3.16 \mathrm{~m}$ above the floor. The ventilation rate of the chamber was 2.2 air changes per hour ( $\mathrm{ACH})$. Comparisons between simulation and measurement results along five sampling lines in the chamber are illustrated in Figure 3, showing good agreement between the two datasets (with an error of less than $1{ }^{\circ} \mathrm{C}$ in temperature and $0.1 \mathrm{~m} / \mathrm{s}$ in velocity). Therefore, this simulation method was considered as accurate and usable in this study.

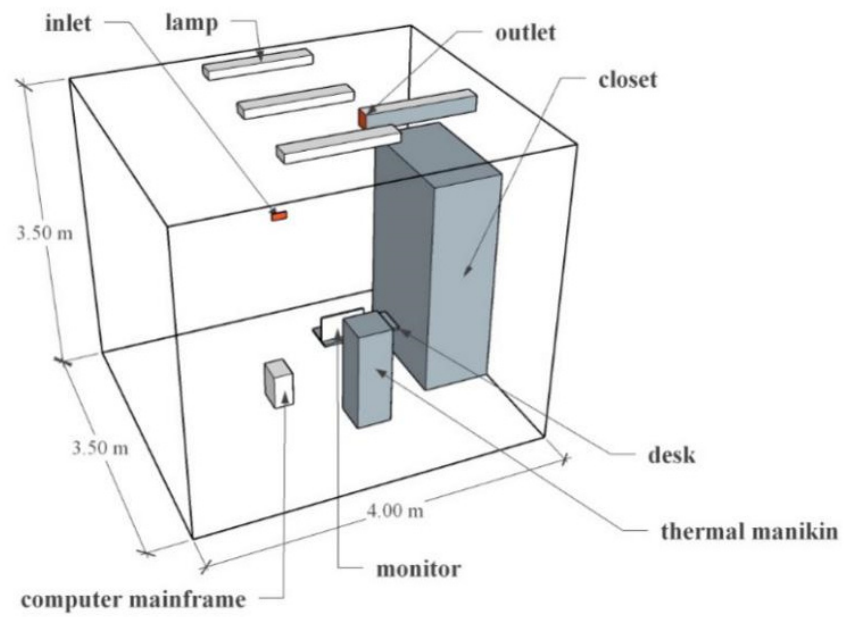

Figure 2. Configuration of the test chamber. 


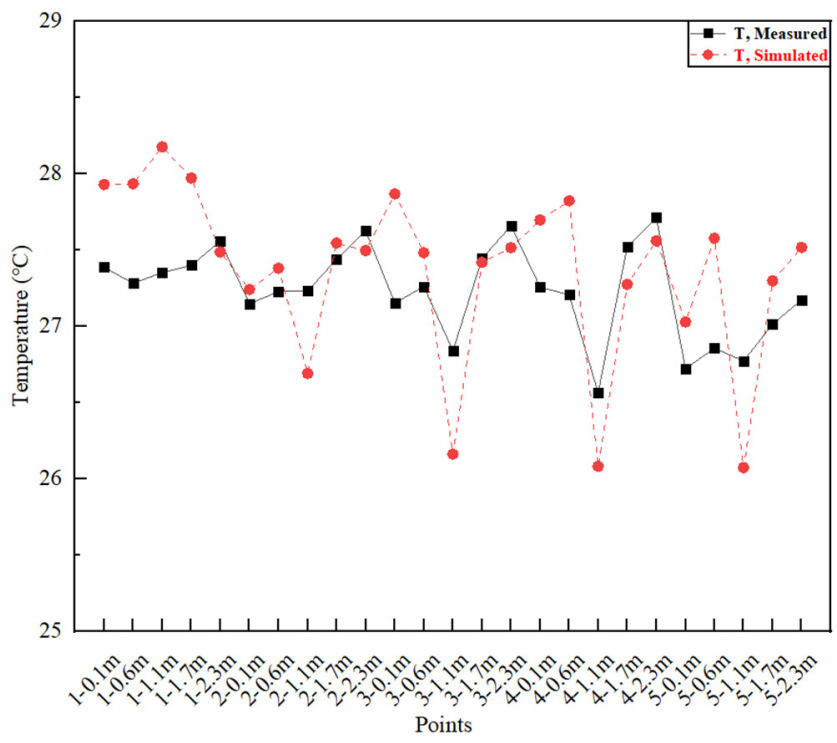

(a) Verification of temperature

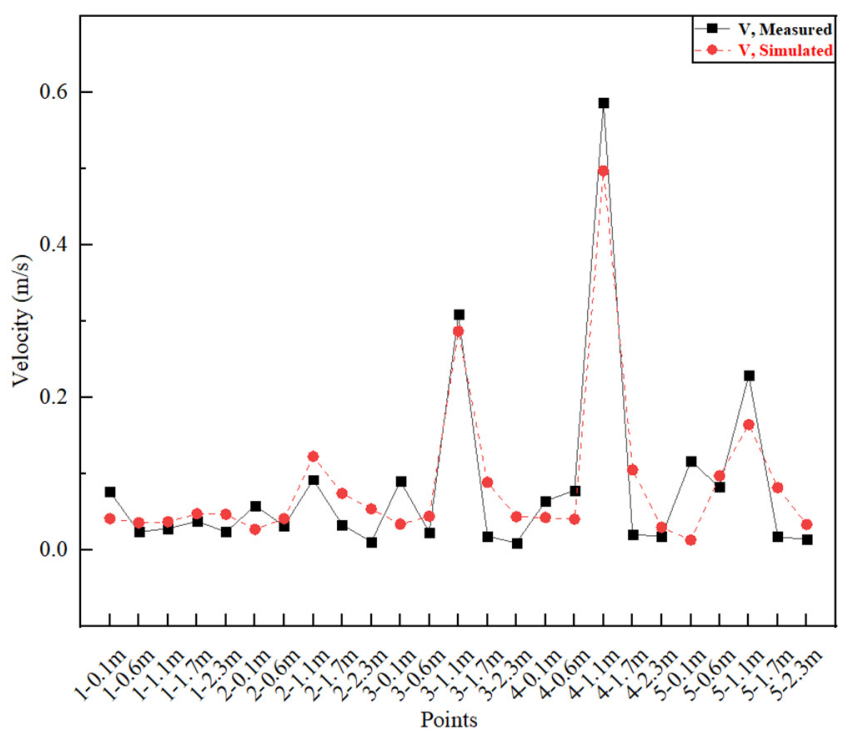

(b) Verification of velocity

Figure 3. Comparison between simulated and measured data at 5 heights at sampling lines 1-5 (remarks: measurement point $\mathrm{X}-\mathrm{Y} \mathrm{m}$, where $\mathrm{X}$ is the number sampling line and $\mathrm{Y}$ is the heights of $0.1 \mathrm{~m}, 0.6 \mathrm{~m}, 1.1 \mathrm{~m}, 1.7 \mathrm{~m}$ and $2.3 \mathrm{~m})$.

\subsection{Description of the Model and Simulation}

As shown in Figure 4, a typical office model has been established in this study, with dimensions of $14 \mathrm{~m}$ (length) $\times 10 \mathrm{~m}$ (width) $\times 4 \mathrm{~m}$ (height). There were four air supply inlets on the ceiling and four air exhaust outlets at the bottom of the two opposite walls. The walls, the ceiling, and the floor of this office were all thermally insulated. There were 6 lamps and 24 working positions (each with a person and a computer) in the office. To simplify the computational model, the radiative heat transfer of the walls and floor were considered as one heat source. Similarly, the radiative heat transfer of the ceiling and the heat emission from six lamps were considered as one heat source. This left the heat emission from four adjacent working positions, which were considered as one heat source. Therefore, there were a total of nine heat sources in this simulation work. The numerical method for calculating the temperature distribution of this office has been described above, and the specific boundary conditions are listed in Table 1 . The neutral temperature in 
the office was assumed to be $25^{\circ} \mathrm{C}$. The office was discretized into $5,800,535,7,784,596$, and 10,746,488 hexahedral control volumes. After a grid-independence test, the middle definition was adopted to balance accuracy and time.

Table 1. Summary of numerical simulation conditions.

\begin{tabular}{cc}
\hline Surface & Boundary Condition \\
\hline Walls/Ceiling/Floor & Wall; Adiabatic \\
Lamp & Wall; Heat flux: $150 \mathrm{~W} / \mathrm{m}^{2}$. \\
Person & Wall; Heat flux: $45 \mathrm{~W} / \mathrm{m}^{2}$ \\
Computer & Wall; Heat flux: $70 \mathrm{~W} / \mathrm{m}^{2}$ \\
Air supply & Oelocity-inlet; Velocity: $1.0 \mathrm{~m} / \mathrm{s}$. Temperature: $21^{\circ} \mathrm{C}$ \\
Air exhaust & Outflow \\
\hline
\end{tabular}

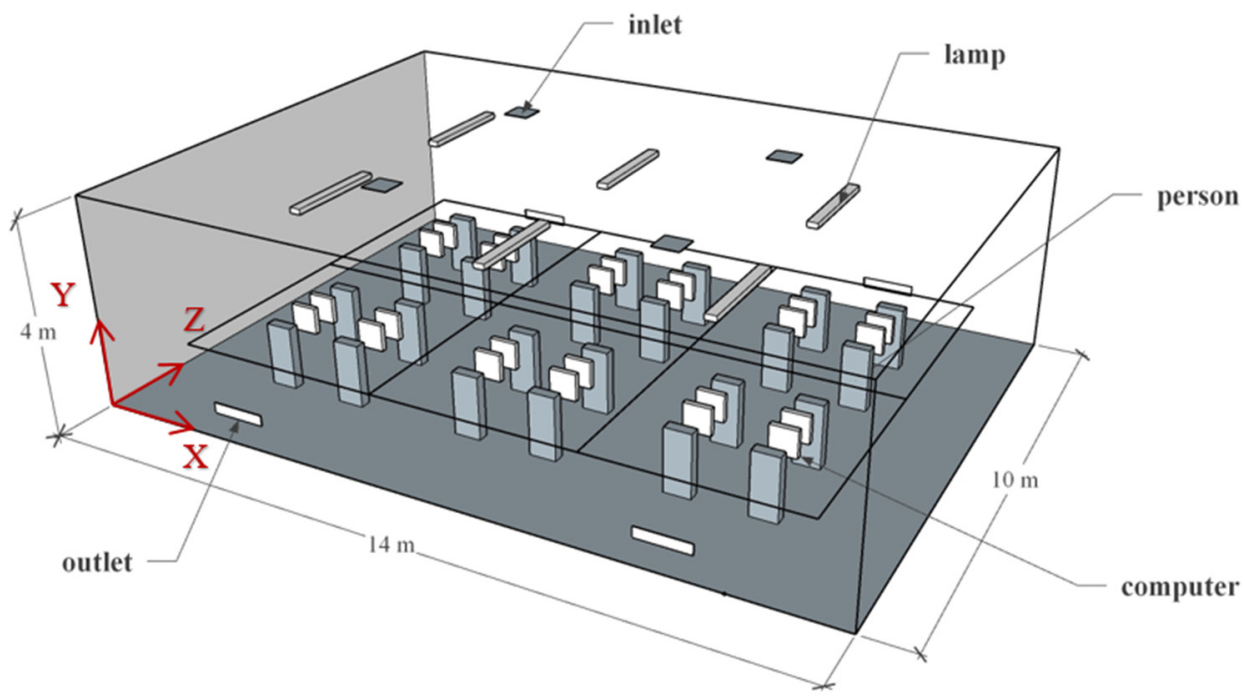

Figure 4. A model for the office.

According to the coupled calculation results of both convective and radiative heat transfers, the airflow field and the temperature field can be obtained. The cross sections $y=1.0 \mathrm{~m}$ and $z=2.1 \mathrm{~m}$ were taken as examples, with the velocity distribution and the temperature distribution are shown in Figures 5 and 6, respectively. The calculation results showed that the air was supplied vertically from the inlet toward the floor, with observable backflow along the floor and the walls. Simultaneously, the air supply directly reached the working area, which could effectively take away internal heat emissions and diffuse them to other places. Near the working positions, the air was warmed up significantly, so a heat plume around them could be observed. Due to the effect of backflow and buoyancy, the temperature distribution in the room was obviously stratified from bottom to top.

The sub-temperature distribution of each heat source was calculated with the airflow field described above. Taking one working position as an example, its CRI distribution obtained by Equation (1) is shown in Figure 7. The calculation results showed that the CRI of the heat emission from one working position (with four people and four computers) ranged between 0 and 4.67. It could be observed that near this heat source, the CRI was greater than 1.0. However, with the increase in distance, the heat diffusion was weakened. The CRI thus was less than 1.0 in most areas, meaning that the heat source had an obvious effect on the area around it, but a relatively small effect at larger distances. 

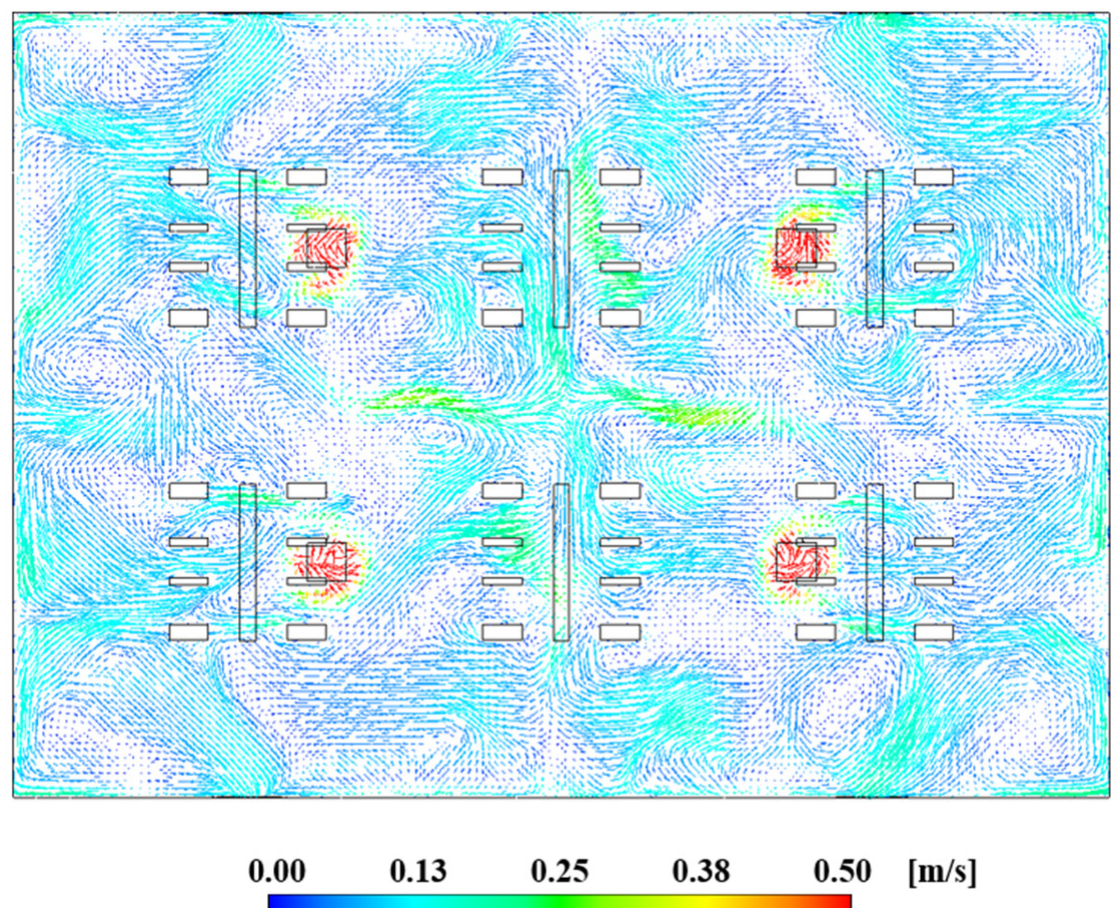

(a) Velocity distribution ( $y=1.0 m$ cross section)

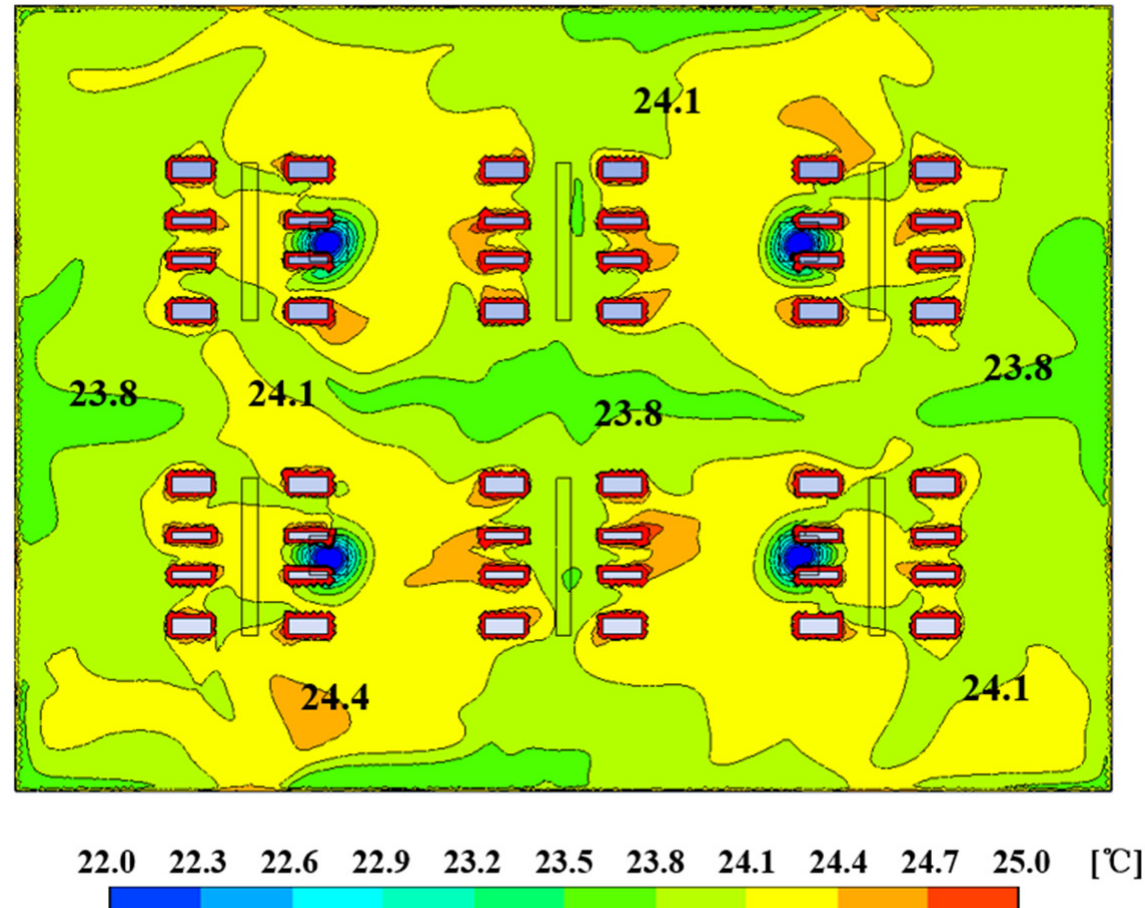

(b) Temperature distribution ( $y=1.0 \mathrm{~m}$ cross section)

Figure 5. Velocity and temperature distributions ( $y=1.0 \mathrm{~m}$ cross section). 


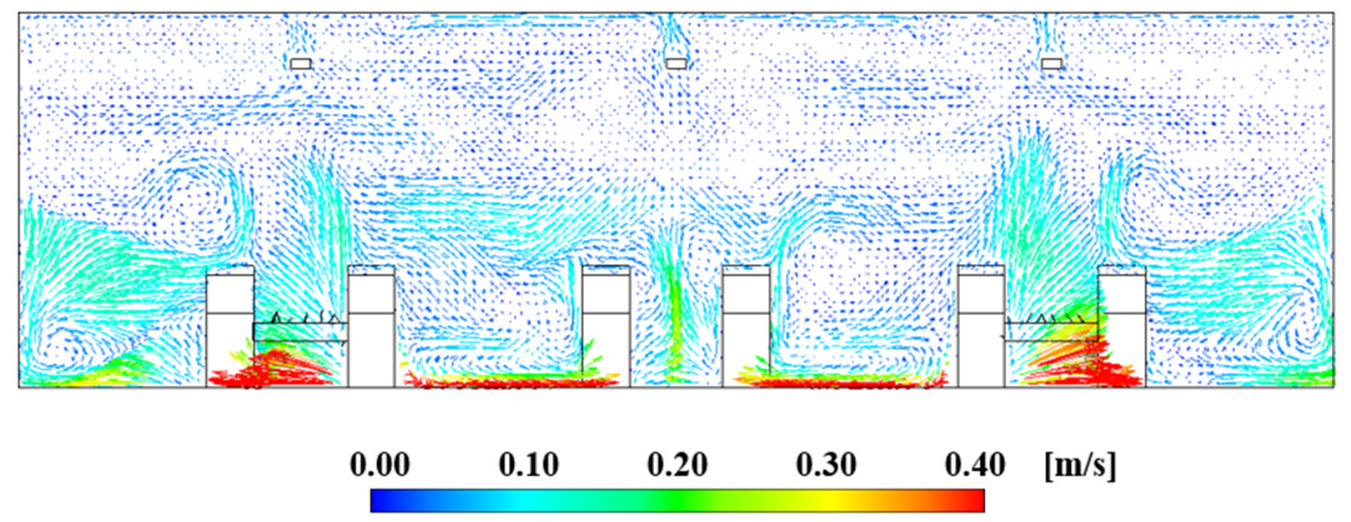

(a) Velocity distribution ( $z=2.1 \mathrm{~m}$ cross section)

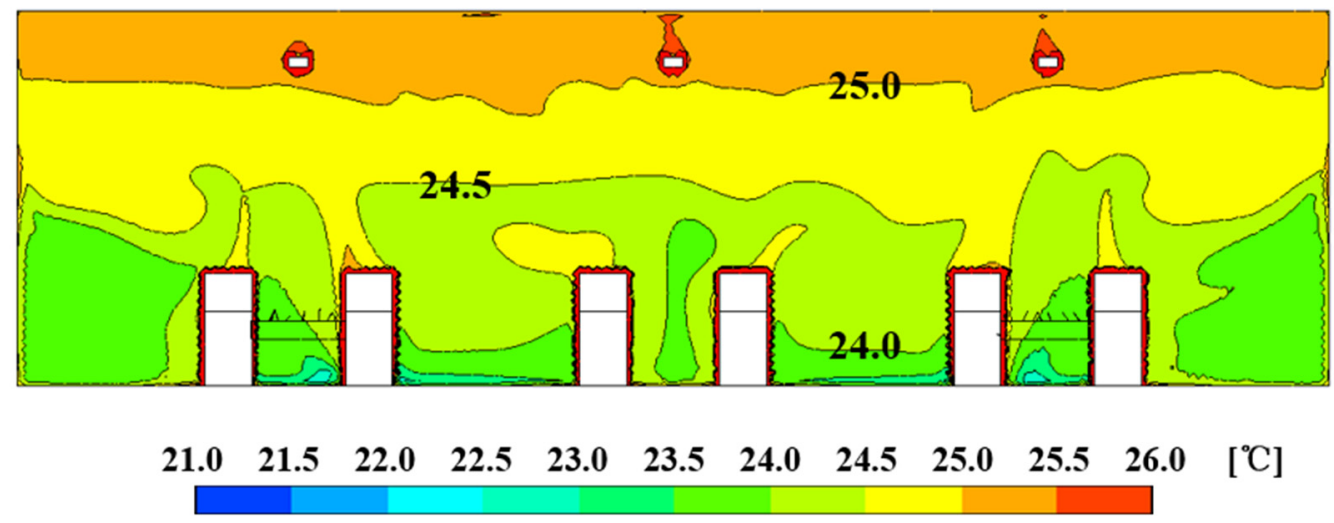

(b) Temperature distribution ( $z=2.1 \mathrm{~m}$ cross section)

Figure 6. Velocity and temperature distributions ( $z=2.1 \mathrm{~m}$ cross section).

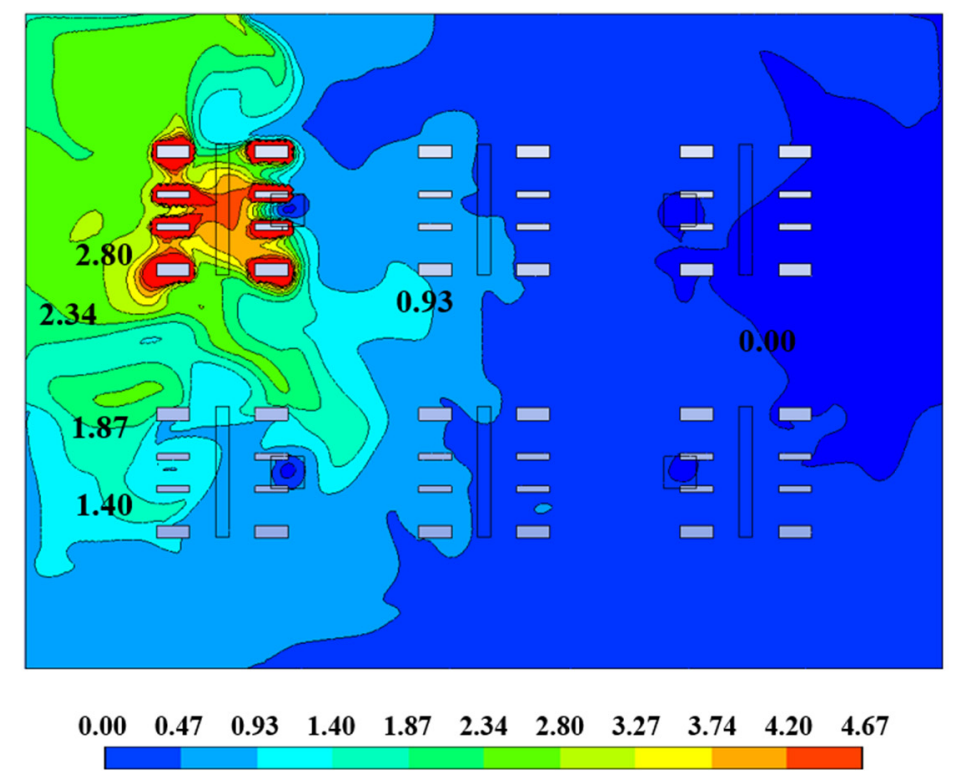

Figure 7. CRI distribution of the heat emission from the one working position (with four people and four computers) ( $y=1.0 \mathrm{~m}$ cross section). 


\section{Results}

\subsection{Comparison on Prediction Accuracy between Fixed Sensors and Mobile Sensors}

In the comparison, 10 temperature prediction points in the plane with the height of $1 \mathrm{~m}, 2 \mathrm{~m}$ and $3 \mathrm{~m}$, respectively, were selected. They were named as L-1 to L-10, M-1 to $\mathrm{M}-10$, and $\mathrm{H}-1$ to $\mathrm{H}-10$, respectively. It should be noted that in this study the locations of all prediction points were only different in height, but with identical plane coordinates. According to the requirements of the prediction algorithm, the number of collected air temperature measurements needs to be equal to the number of heat sources. Therefore, nine air temperatures were collected. The fixed sensor locations are shown in Figure 8. It is worth noting that the acquisition location of the sensors has a great impact on the prediction results. In other words, even if the number of sensors is the same, different results and prediction accuracy will be obtained by using the proposed algorithm with different acquisition locations. For example, in the study of Sasamoto et al. [35], the fixed sensors were installed near each heat source, and the prediction accuracy was acceptable. There are two reasons why fixed sensors were all installed on the walls in this study: (1) This is more suitable for the actual situation; (2) The purpose of this study is to verify the application disadvantages of fixed sensors. That is, taking the actual situation as a reference, the limitations of fixed sensors are analyzed and further the solutions are proposed. Meanwhile, a mobile sensor with the acquisition height of $1.2 \mathrm{~m}$ was used to collect the air temperature at several locations in the space, also shown in Figure 8. The above two groups of collected air temperatures were used to predict the temperature of 30 points at the three heights, with their prediction results shown in Figure 9.

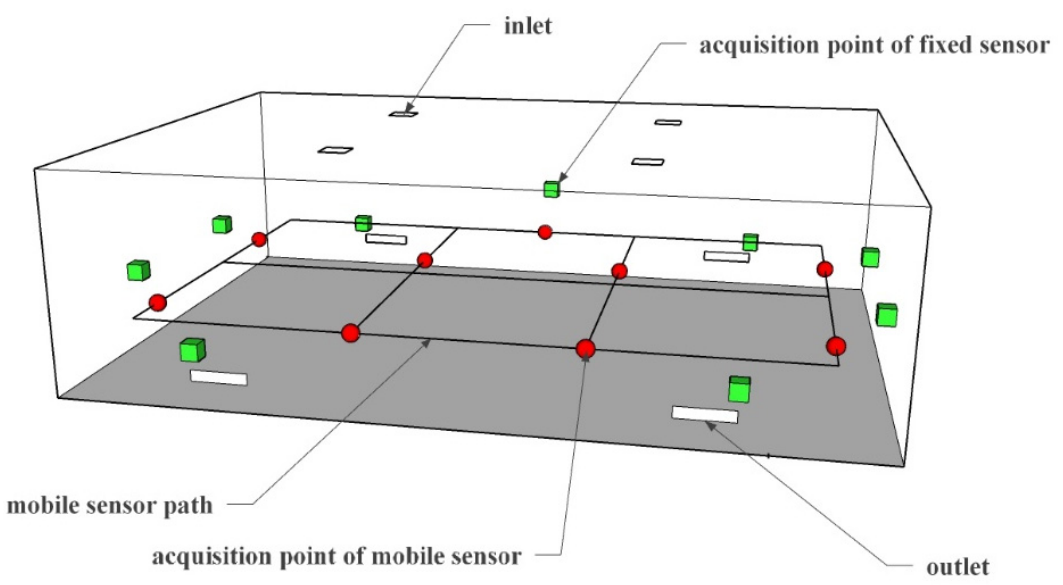

Figure 8. Acquisition points of fixed sensors and mobile sensors.

When the air temperature collected by fixed sensors was used for prediction, according to Table 2, the corresponding average relative errors were $5.7 \%, 10.8 \%$, and $27.7 \%$ at the heights of $h=1.0 \mathrm{~m}, \mathrm{~h}=2.0 \mathrm{~m}$, and $\mathrm{h}=3.0 \mathrm{~m}$, respectively, which were relatively large. The reasons for the unsatisfactory results are considered as follows:

Table 2. Prediction of each point using fixed sensors and mobile sensors.

\begin{tabular}{ccc}
\hline Average Relative Error & Fixed Sensors & Mobile Sensors \\
\hline At the height of $\mathrm{h}=1.0 \mathrm{~m}$ & $5.7 \%$ & $2.1 \%$ \\
\hline At the height of $\mathrm{h}=2.0 \mathrm{~m}$ & $10.8 \%$ & $3.3 \%$ \\
\hline At the height of $\mathrm{h}=3.0 \mathrm{~m}$ & $27.7 \%$ & $4.8 \%$ \\
\hline
\end{tabular}

First, the influence of the acquisition locations of the sensors on the prediction accuracy noted above cannot be ignored. Second, we suppose that it is mainly related to the influence of airflow distribution. The proposed prediction algorithm consists of two parts: the CRI 
matrix and the air temperature matrix. The assumption of a steady airflow field is the basic premise for calculating CRI. Specifically, when the airflow field is dominated by forced convection in the room, although the influences from other heat sources exist, the effect is smaller than that of forced convection, and thus can be ignored. That is, the airflow field can be considered as steady for a small variation range of supply air temperature and velocity. However, this is an ideal assumption, which has deviation in practical applications. For example, near the walls, air supply/exhausts, and local heat sources, due to the influence of boundary layer, air backflow and heat plume, the airflow distribution in these areas is complex and unstable, resulting in large errors in the calculation of CRI. In the proposed prediction algorithm, the application of sensors used to collect air temperature is combined with CRI to calculate the heat source intensity. Therefore, when using the fixed sensors on the walls with unstable airflow distribution to predict the temperature distribution, the inaccurate calculation of CRI at any sensor location was used repeatedly to calculate the intensity of each heat source. This leads to the influence of each CRI calculation error being superimposed and expanded, further affecting the prediction accuracy. This is the main reason for the lower prediction accuracy when using fixed sensors to predict temperature distribution.

Especially, Figure 9 showed that when using fixed sensors for temperature prediction, obvious abnormalities occurred at some locations, such as L-7, L-8, H-1, and H-10. In addition to the reasons noted above, we assume their locations also have an impact on the prediction accuracy. L-7 and L-8 were located at the lower part of the wall and close to the supply air, which was more vulnerable to the influence of air backflow after the supply air meets the floor and other surfaces. Therefore, it will affect the CRI calculation of each heat source here and further affect the prediction accuracy. Similarly, H-1 and H-10 were located at the higher part of the wall and close to the corner of the room. The airflow distribution here is affected by many factors, such as air backflow near the adjacent walls, heat plume above the heat source, etc. The prediction error thus also increases.

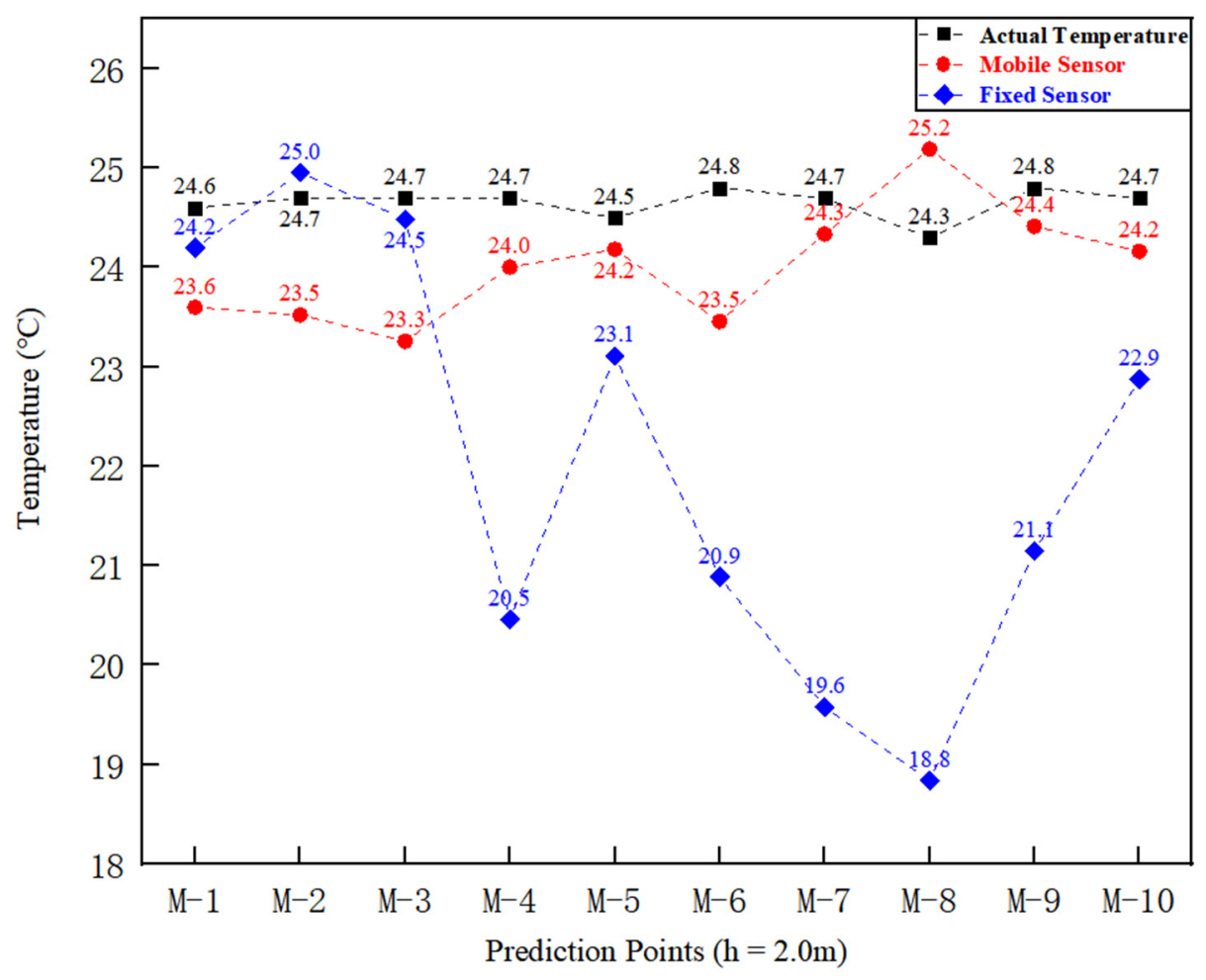

(a) Prediction at the height of $1.0 \mathrm{~m}$ using fixed sensors and mobile sensors

Figure 9. Cont. 


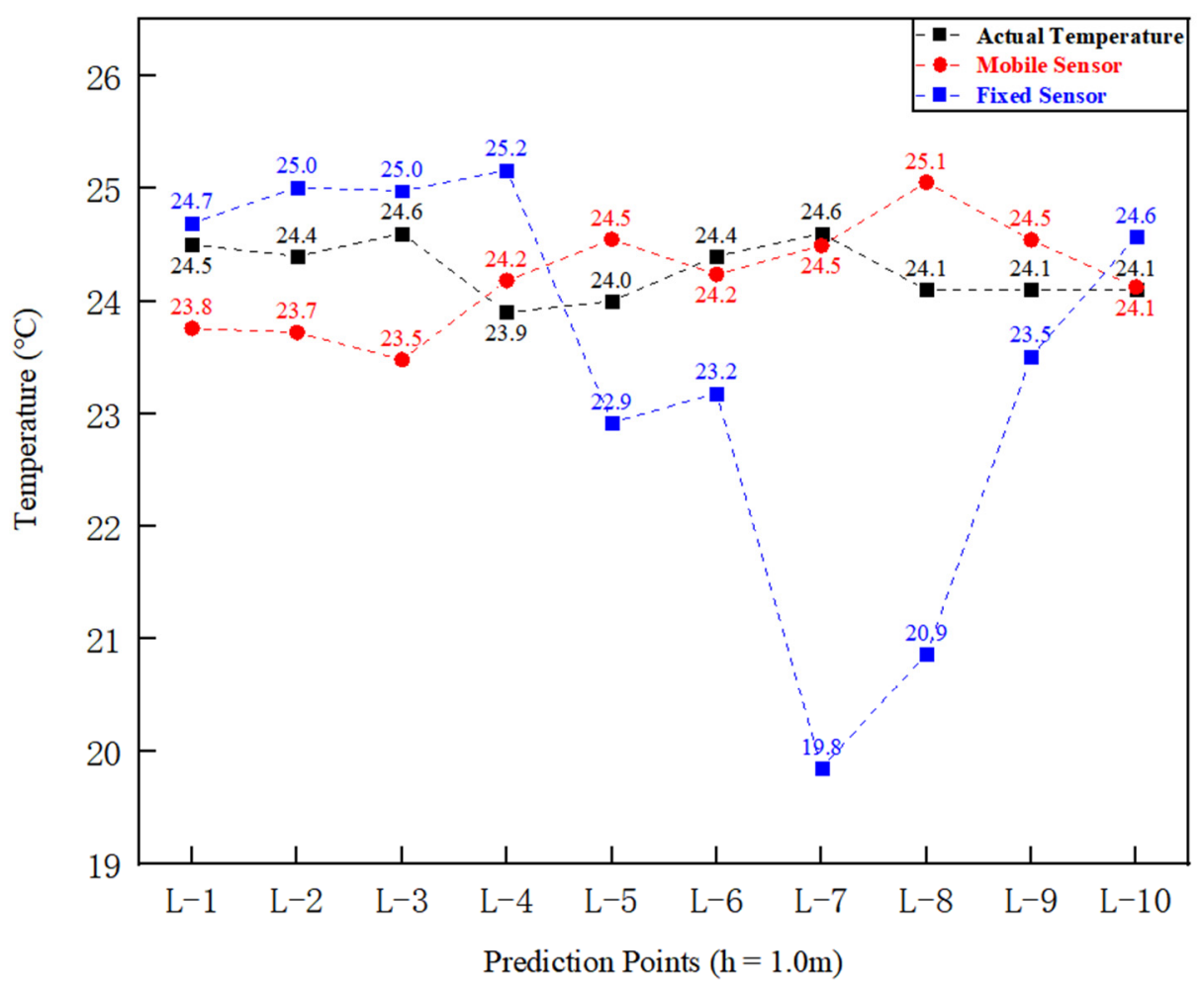

(b) Prediction at the height of $2.0 \mathrm{~m}$ using fixed sensors and mobile sensors

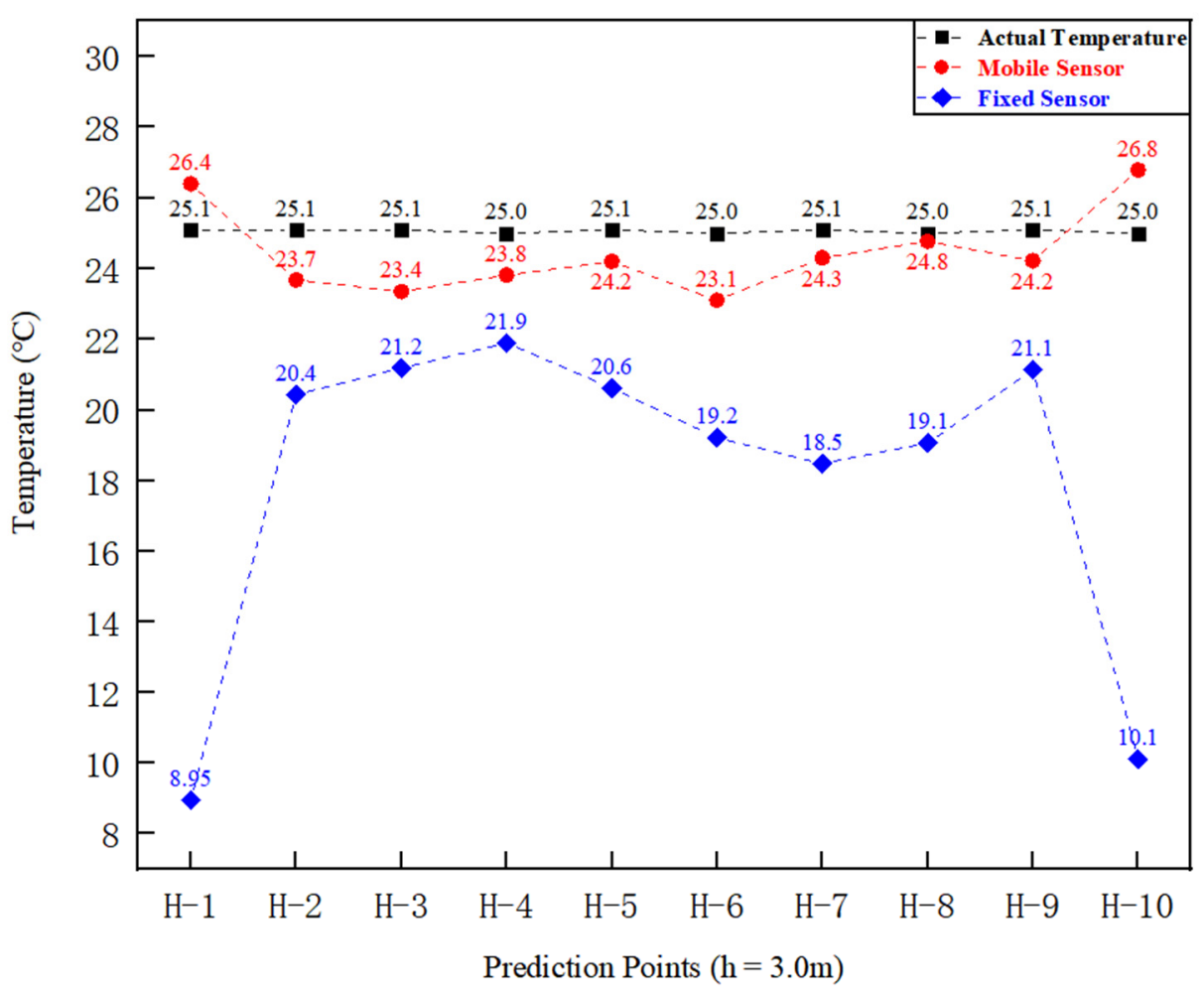

(c) Prediction at the height of $3.0 \mathrm{~m}$ using fixed sensors and mobile sensors

Figure 9. Prediction of different heights using fixed sensors and mobile sensors. 
When using the mobile sensors with flexible acquisition locations instead of the fixed sensors for temperature prediction, the corresponding average relative errors were $2.1 \%$, $3.3 \%$, and $4.8 \%$, respectively. This shows that the proposed temperature distribution prediction method based on CRI and finite air temperature is reliable, which is consistent with the research results of Sasamoto et al. [35]. Additionally, this indicates that due to some restrictions in practical applications, using mobile sensors instead of fixed sensors to predict the temperature distribution is appropriate. Besides, not in all cases, the prediction results obtained by using the mobile sensors are satisfactory.

\subsection{Analysis on the Impact of Mobile Sensors Acquisition Height on Prediction Accuracy}

The height of the mobile sensor can be adjusted in the vertical direction according to the actual situation and the prediction demand. Generally, the purpose of regulating the indoor thermal environment is twofold: reduce energy consumption and maintain comfortable conditions. Therefore, the air temperature within human activity areas is usually the main controlled variable. To figure out the influence of the acquisition height of mobile sensors on the prediction accuracy of this area, 10 prediction points at the heights of $\mathrm{h}=0.7 \mathrm{~m}, \mathrm{~h}=1.0 \mathrm{~m}, \mathrm{~h}=1.2 \mathrm{~m}$ and $\mathrm{h}=1.5 \mathrm{~m}$, named 1-P1 to 1-P10, 2-P1 to 2-P10, 3-P1 to 3-P10, 4-P1 to 4-P10 and 5-P1 to 5-P10, respectively, were selected, with identical plane coordinates. Air temperatures obtained by the mobile sensor introduced in Section 4.1 was used to predict the air temperature at these points, with prediction results shown in Figure 10.

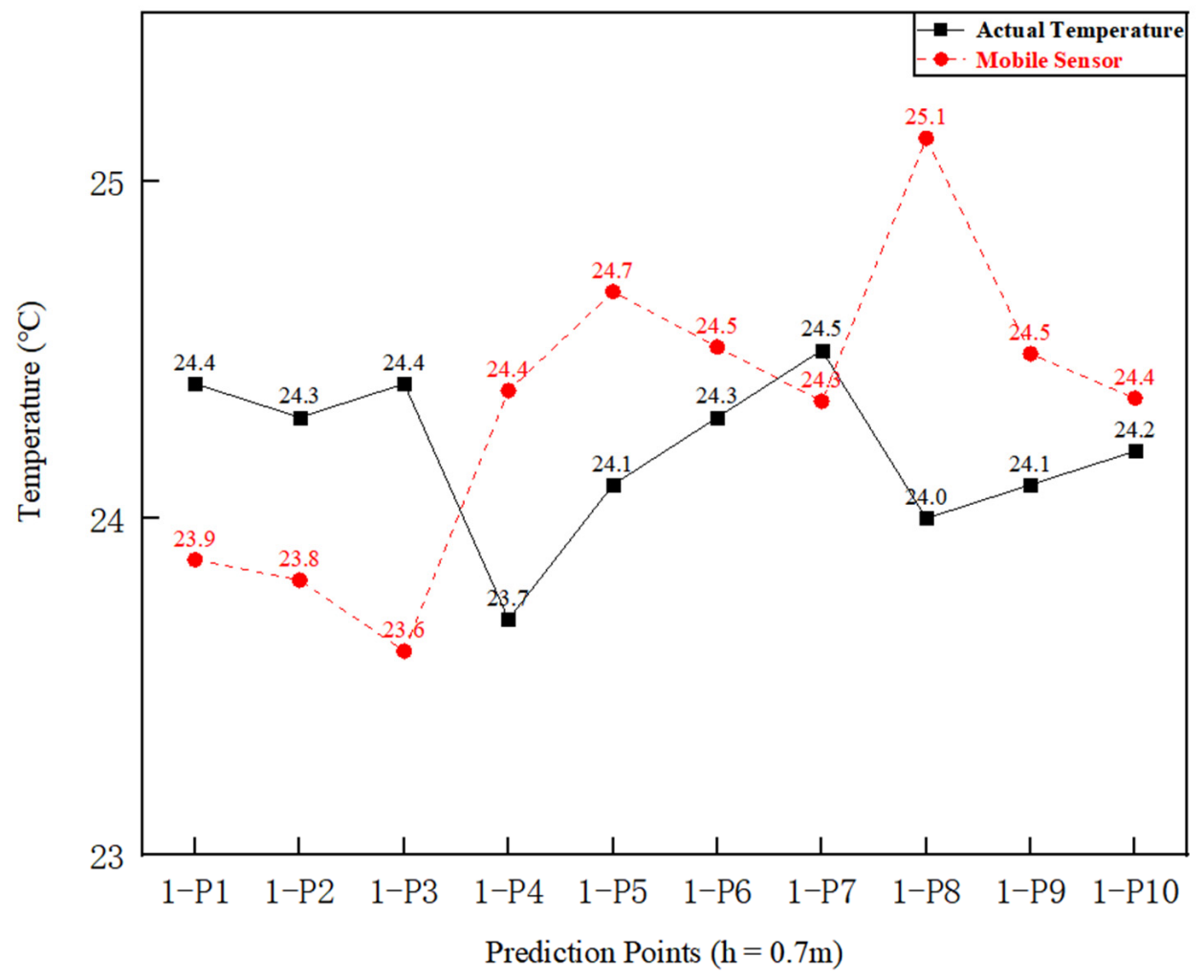

(a) Prediction at the height of $0.7 \mathrm{~m}$ using mobile sensors

Figure 10. Cont. 


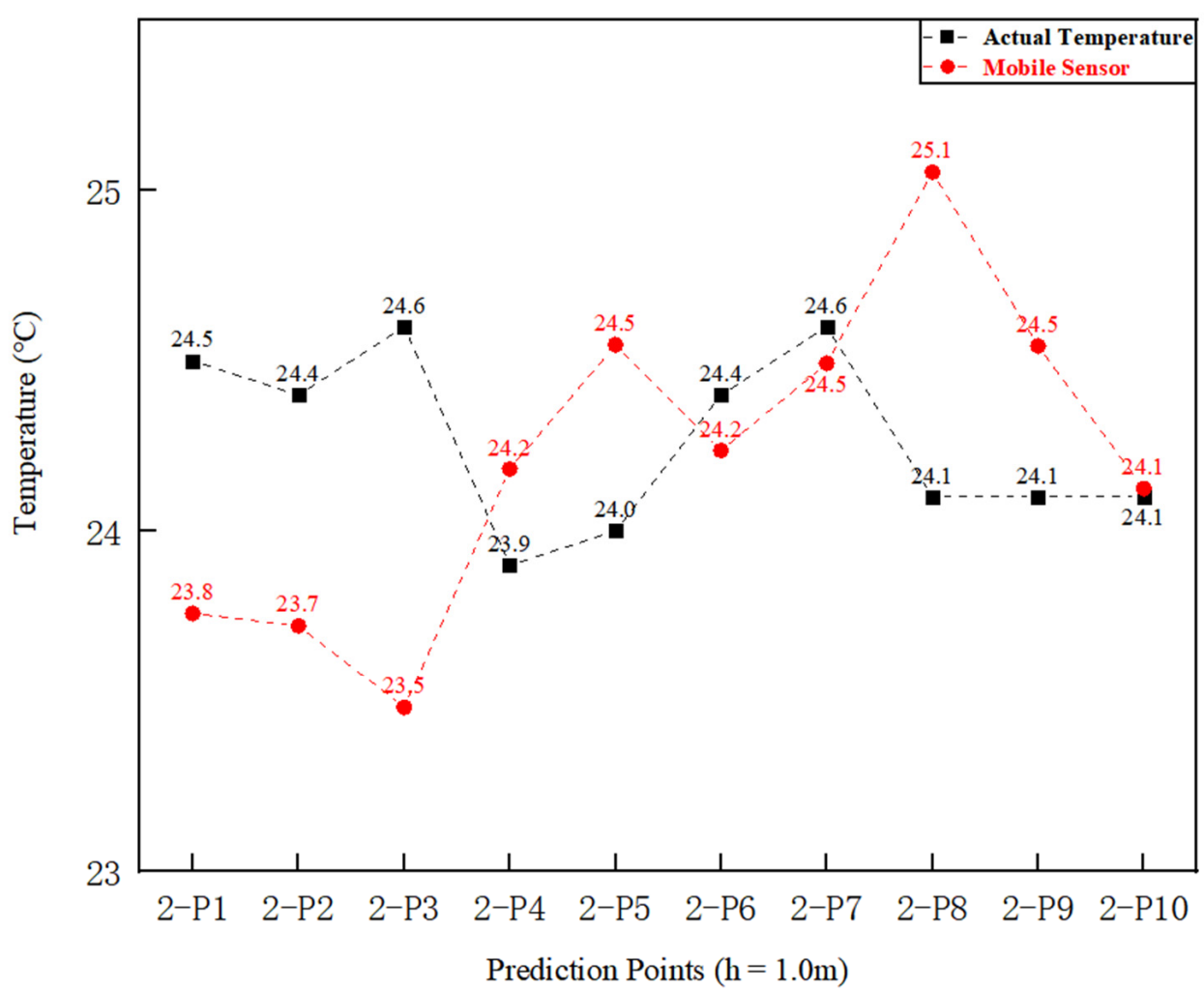

(b) Prediction at the height of $1.0 \mathrm{~m}$ using mobile sensors

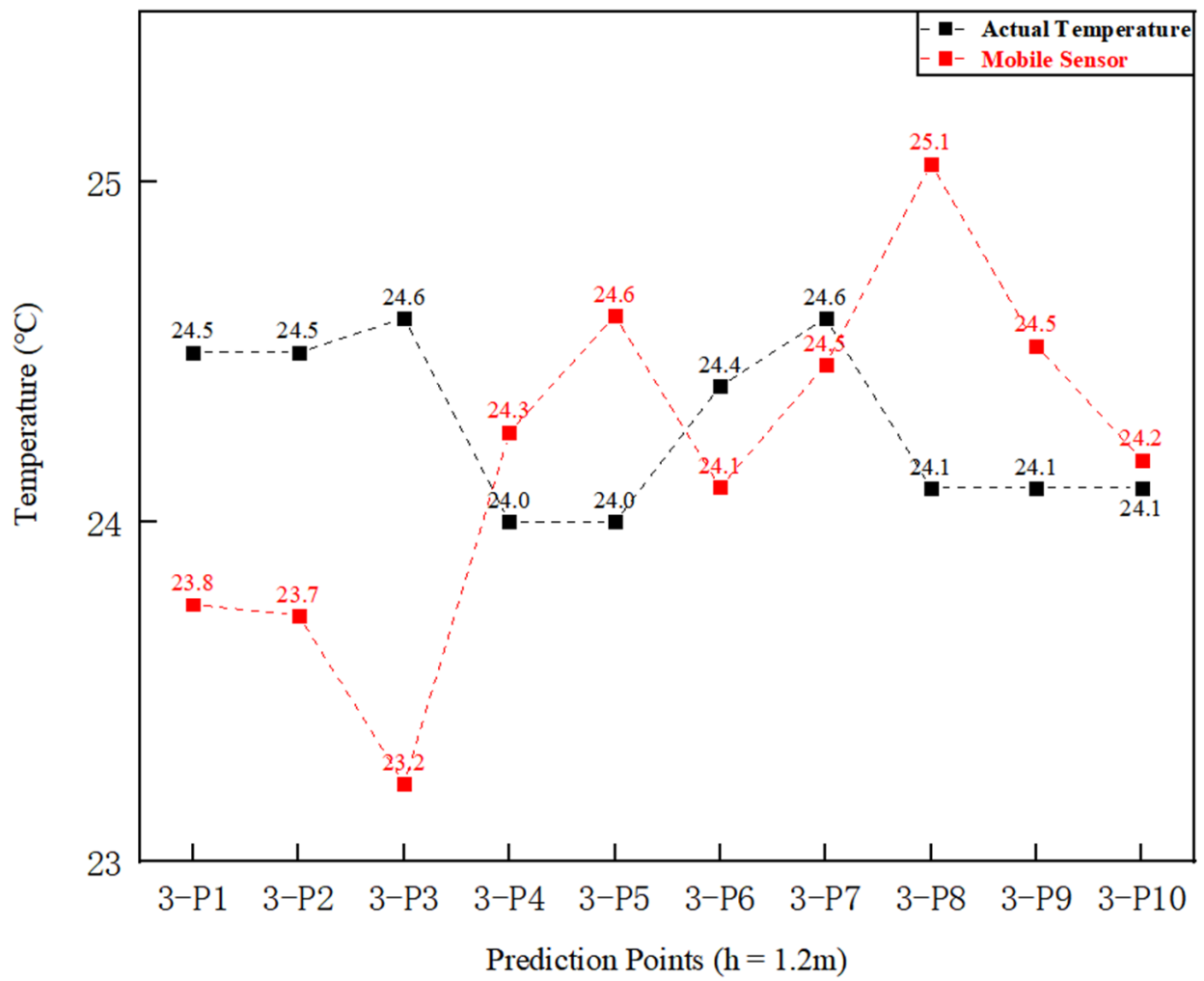

(c) Prediction at the height of $1.2 \mathrm{~m}$ using mobile sensors

Figure 10. Cont. 


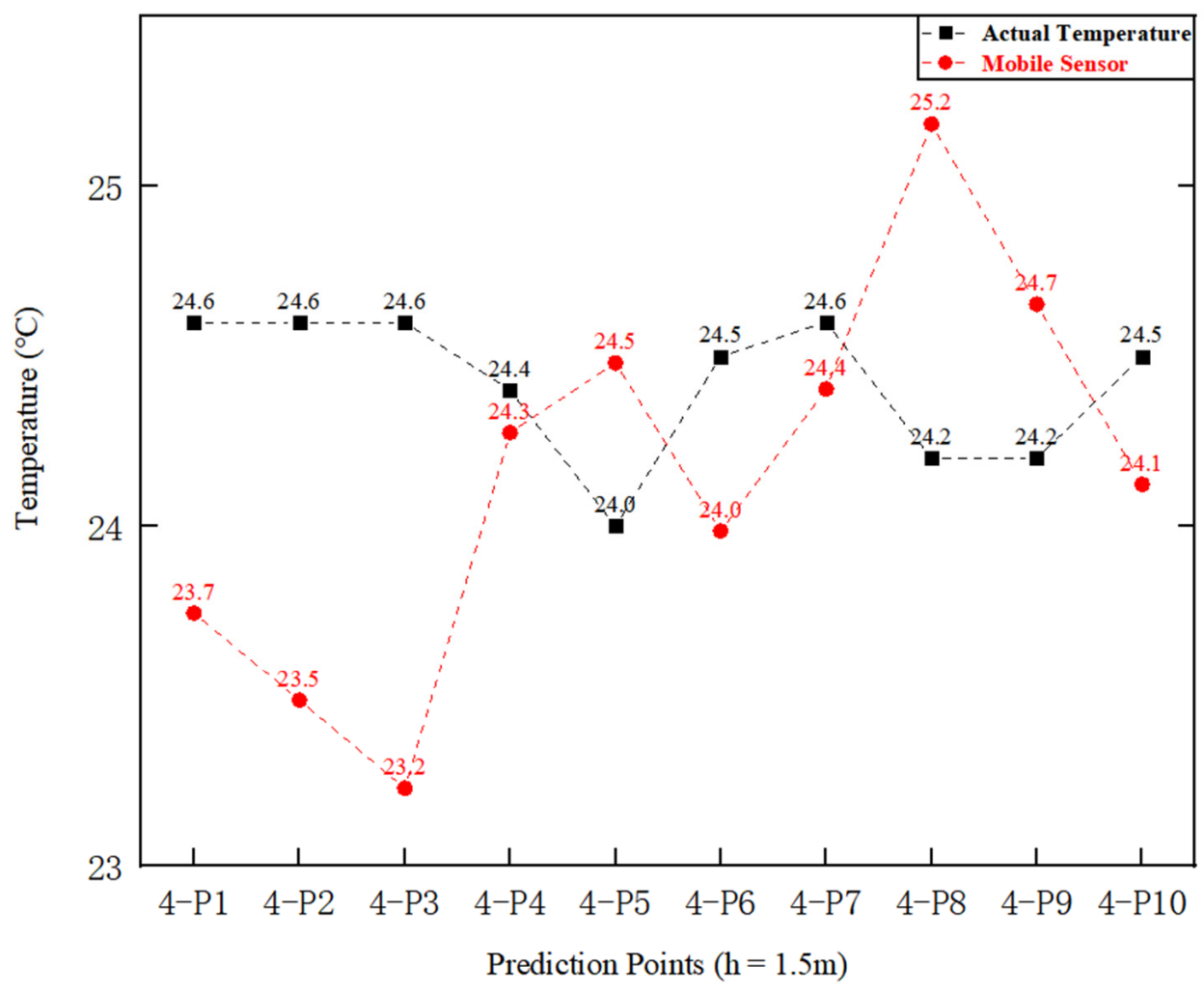

(d) Prediction at the height of $1.5 \mathrm{~m}$ using mobile sensors

Figure 10. Prediction of different heights using mobile sensors.

Similarly, according to Table 3, the corresponding average relative errors were $2.1 \%$, $2.1 \%, 2.3 \%$, and $2.7 \%$ at the heights of $\mathrm{h}=0.7 \mathrm{~m}, \mathrm{~h}=1.0 \mathrm{~m}, \mathrm{~h}=1.2 \mathrm{~m}$, and $\mathrm{h}=1.5 \mathrm{~m}$, respectively. Consequently, it can be concluded that in the human activity area, the acquisition height of mobile sensors has little influence on the prediction accuracy.

Table 3. Prediction of different heights using mobile sensors.

\begin{tabular}{cc}
\hline Average Relative Error & Mobile Sensors \\
\hline At the height of $\mathrm{h}=0.7 \mathrm{~m}$ & $2.1 \%$ \\
\hline At the height of $\mathrm{h}=1.0 \mathrm{~m}$ & $2.1 \%$ \\
\hline At the height $\mathrm{h} h=1.2 \mathrm{~m}$ & $2.3 \%$ \\
\hline At the height of $\mathrm{h}=1.5 \mathrm{~m}$ & $2.7 \%$ \\
\hline
\end{tabular}

\subsection{Analysis on the Impact of Mobile Sensors Acquisition Distance on Prediction Accuracy}

To better guide the application of mobile sensors in practical situations, it should not only consider how to set the acquisition height of mobile sensors, but also consider the acquisition distance of mobile sensors. To explore the impact from this aspect, given a mobile sensor acquisition path (the acquisition height was $1.2 \mathrm{~m}$ ), several acquisition distances were designed, which were $1 \mathrm{~m}, 2 \mathrm{~m}, 3 \mathrm{~m}, 4 \mathrm{~m}$ and $5 \mathrm{~m}$. In the case of each acquisition distance, 3, 3, 3, 3, and 2 acquisition point distributions were given, respectively, as shown in Figures 11-15. The selected prediction points were the same as those at the $1.2 \mathrm{~m}$ height discussed in Section 4.2, named 3-P1 to 3-P10. 


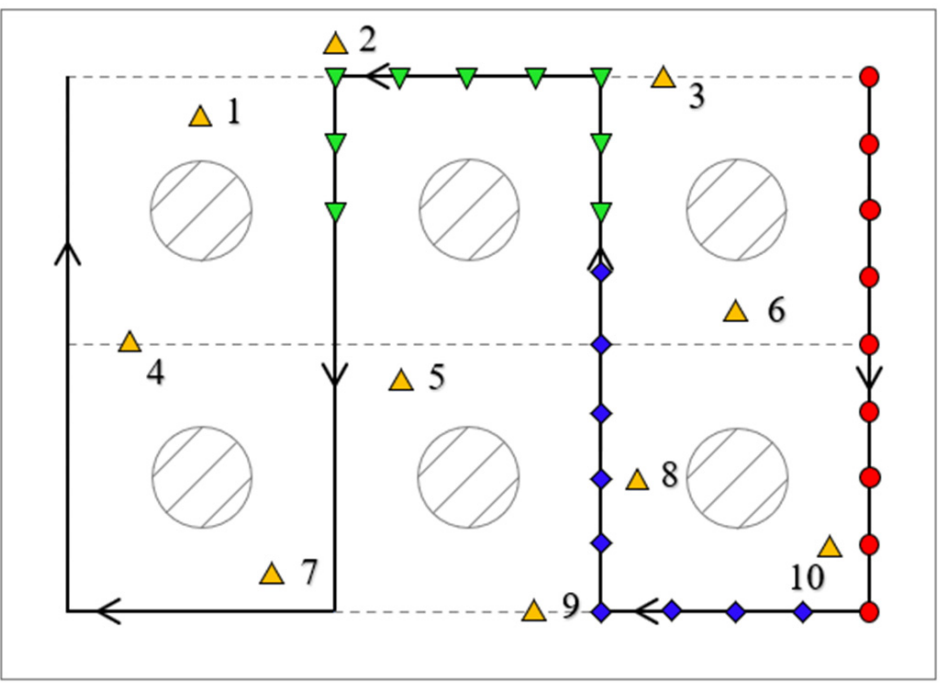

- The 1th distribution of mobile sensors acquisition points (named MS1)

$\checkmark$ - The 2th distribution of mobile sensors acquisition points (named MS2)

$\nabla$ - The 3th distribution of mobile sensors acquisition points (named MS3)

$\triangle$ - Prediction points

(a) Distributions of acquisition points

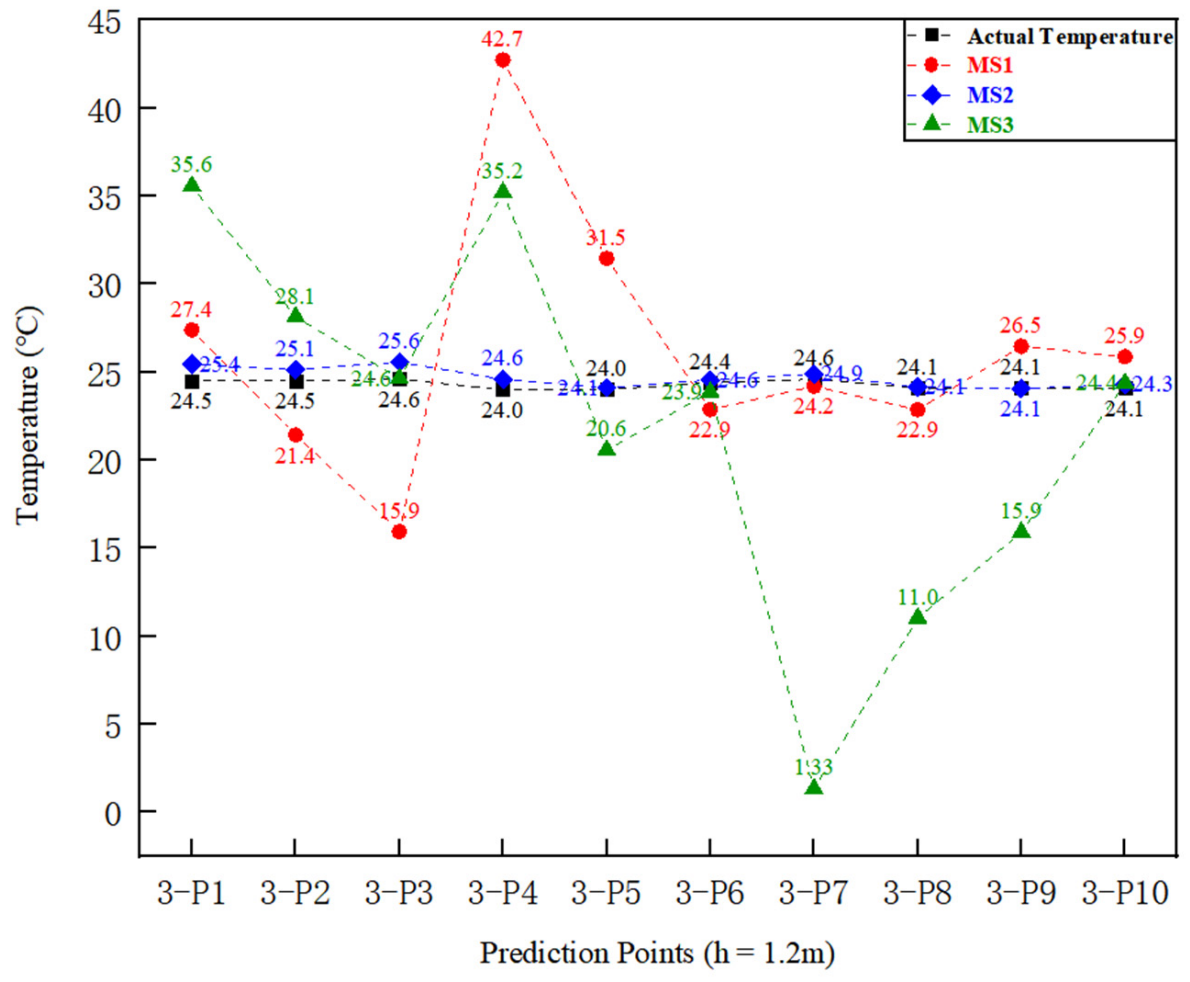

(b) Prediction results

Figure 11. Prediction of mobile sensors with acquisition distance of $1.0 \mathrm{~m}$. 


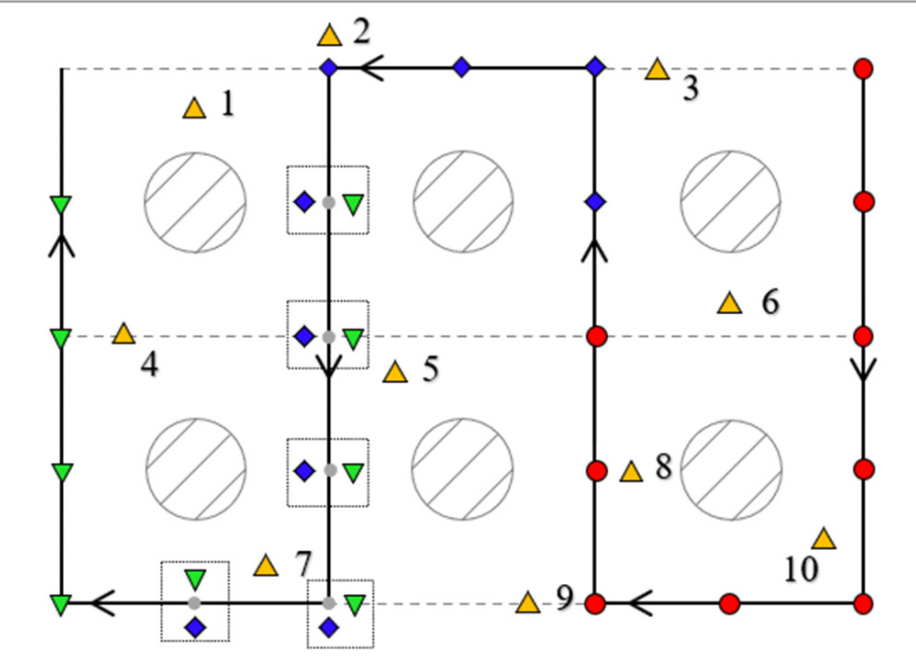

- - The 4th distribution of mobile sensors acquisition points (named MS4)

$\checkmark$ - The 5th distribution of mobile sensors acquisition points (named MS5)

$\nabla$ - The 6th distribution of mobile sensors acquisition points (named MS6)

$\triangle$ - Prediction points

(a) Distributions of acquisition points

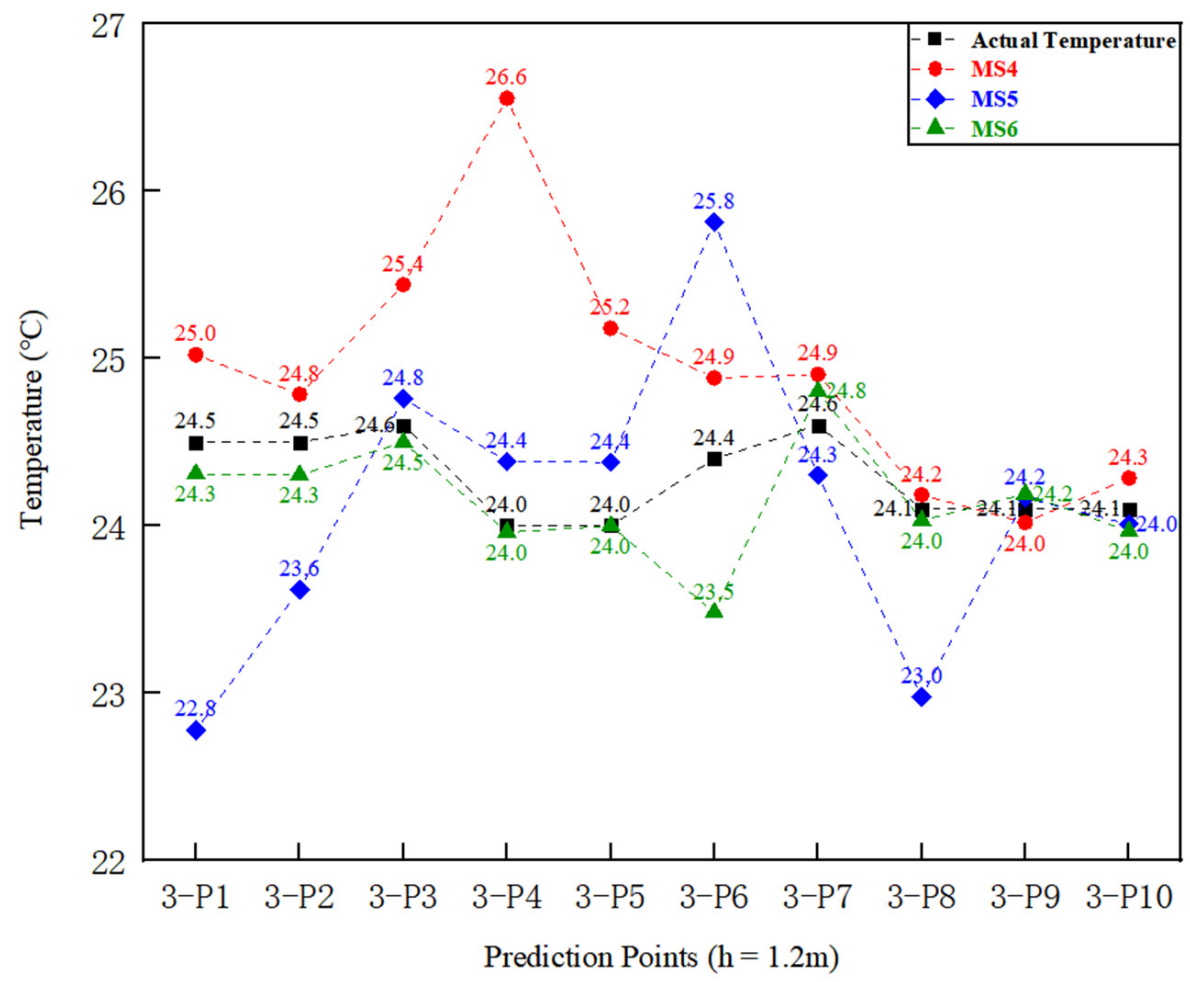

(b) Prediction results

Figure 12. Prediction of mobile sensors with acquisition distance of $2.0 \mathrm{~m}$. 


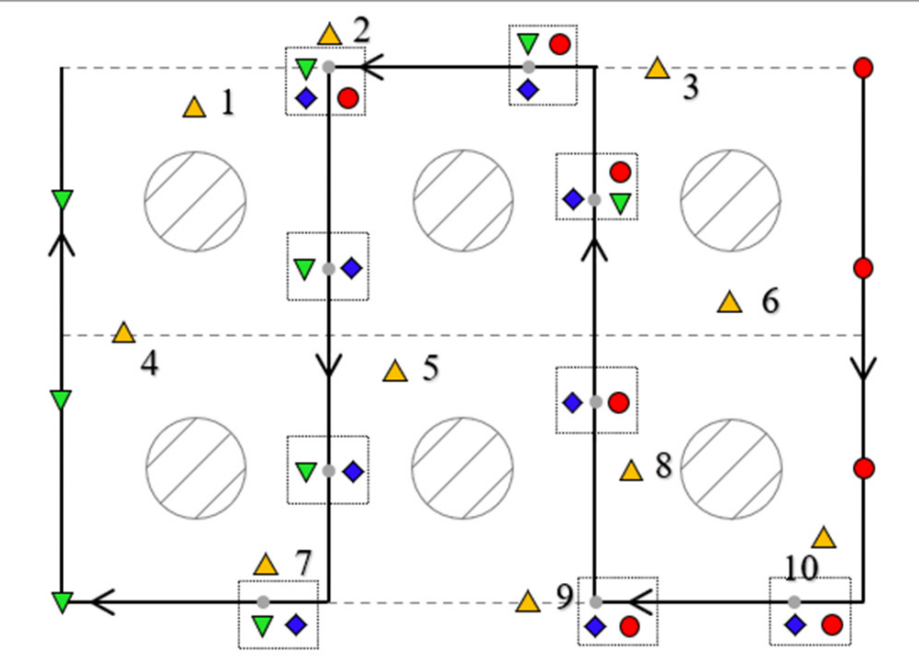

- The 7th distribution of mobile sensors acquisition points (named MS7)

- - The 8th distribution of mobile sensors acquisition points (named MS8)

$\nabla$ - The 9th distribution of mobile sensors acquisition points (named MS9)

$\Delta$ - Prediction points

(a) Distributions of acquisition points

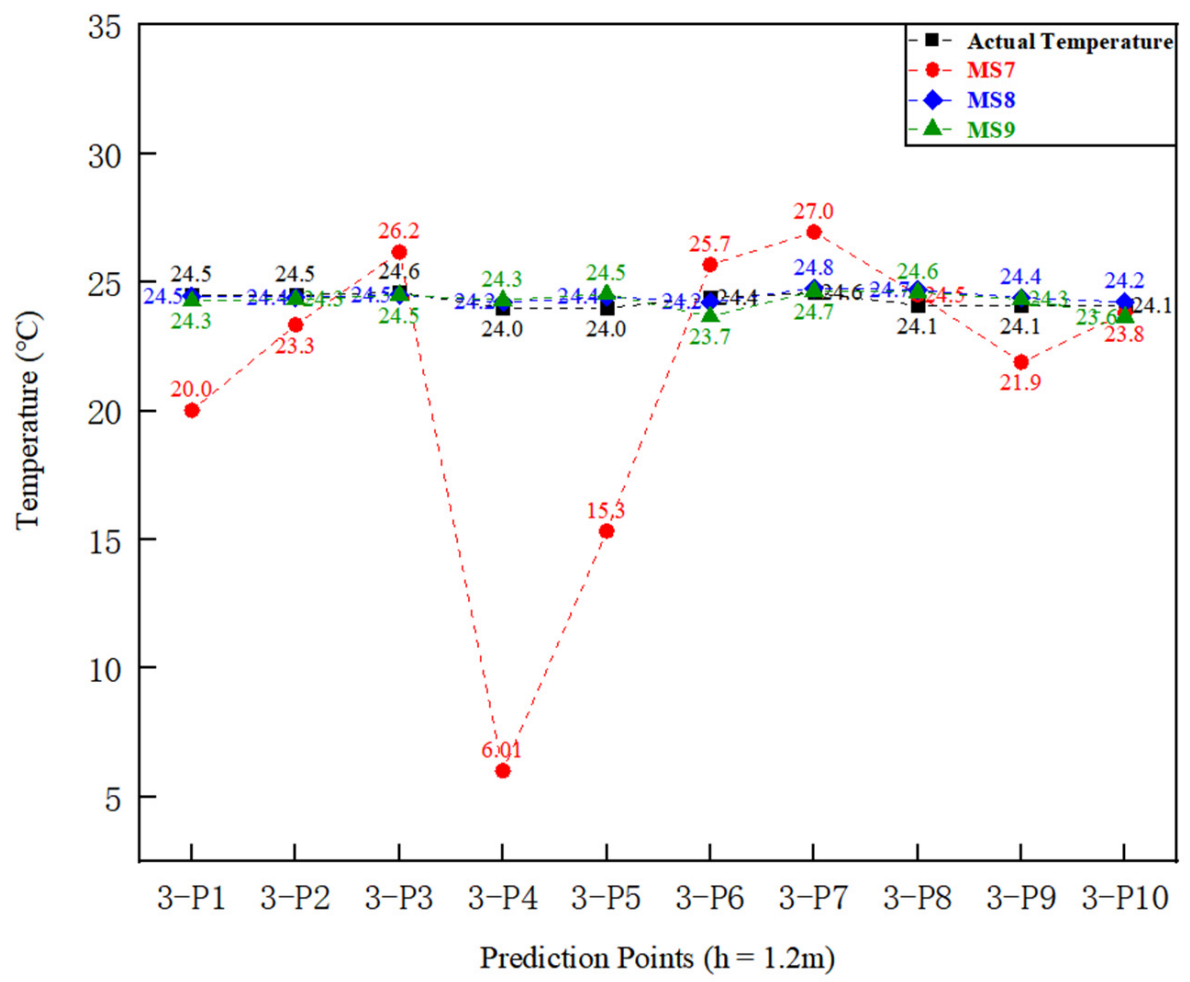

(b) Prediction results

Figure 13. Prediction of mobile sensors with acquisition distance of $3.0 \mathrm{~m}$. 


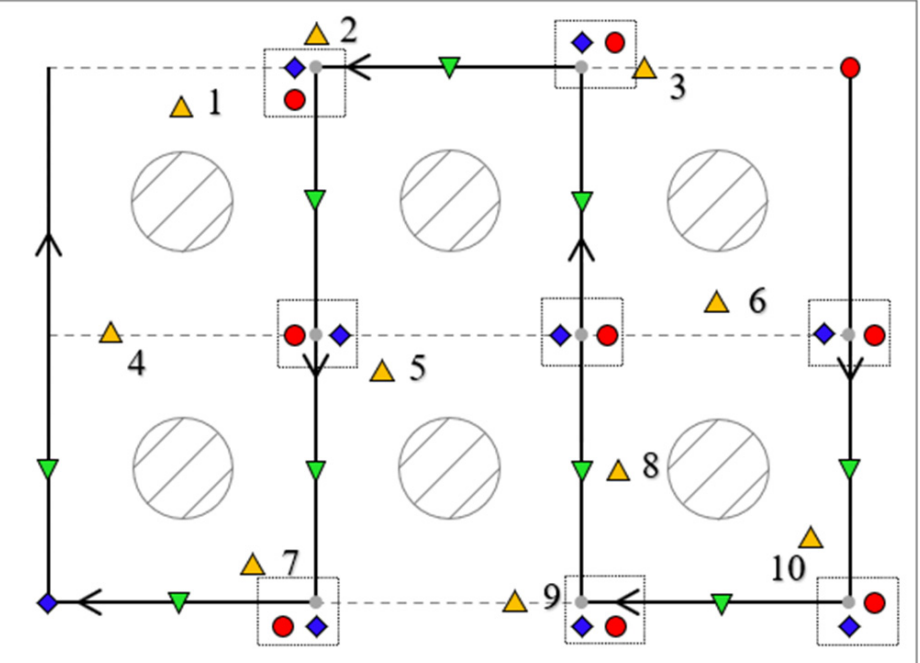

- The 10th distribution of mobile sensors acquisition points (named MS10)

$\checkmark$ - The 11th distribution of mobile sensors acquisition points (named MS11)

$\nabla$ - The 12th distribution of mobile sensors acquisition points (named MS12)

$\triangle$ - Prediction points

(a) Distributions of acquisition points

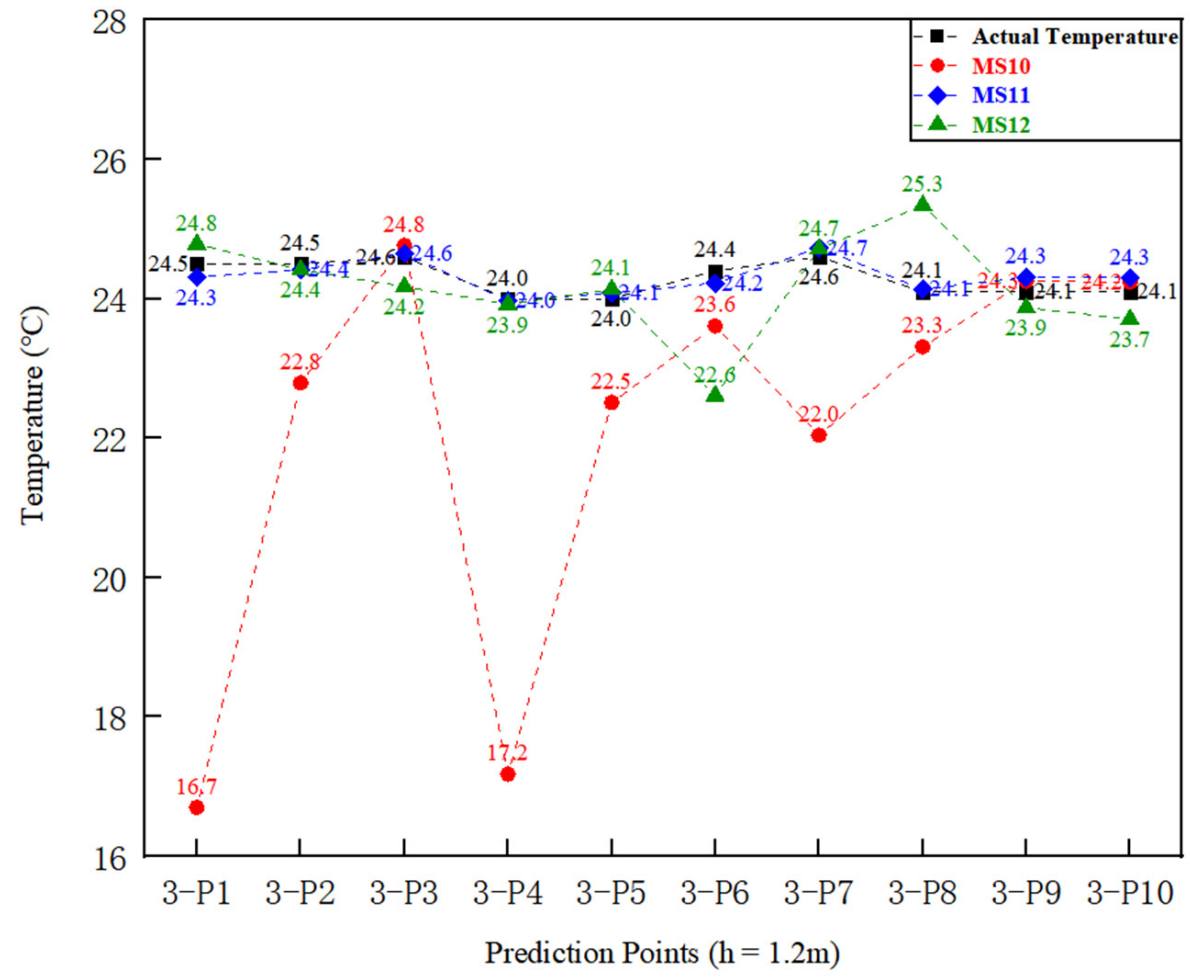

(b) Prediction results

Figure 14. Prediction of mobile sensors with acquisition distance of $4.0 \mathrm{~m}$. 


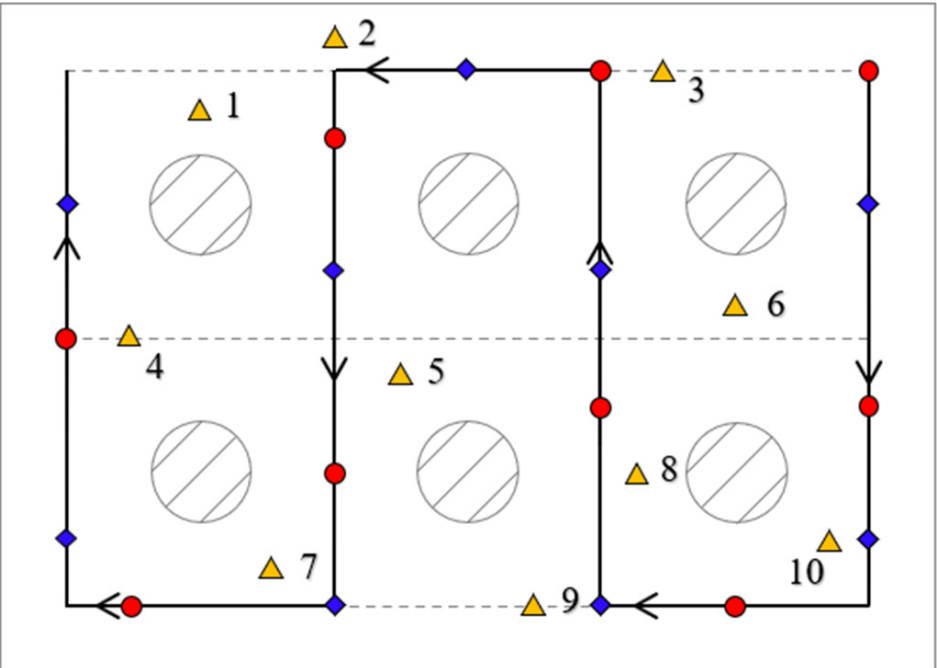

- The 13th distribution of mobile sensors acquisition points (named MS13)

- The 14th distribution of mobile sensors acquisition points (named MS14)

$\Delta$ - Prediction points

(a) Distributions of acquisition points

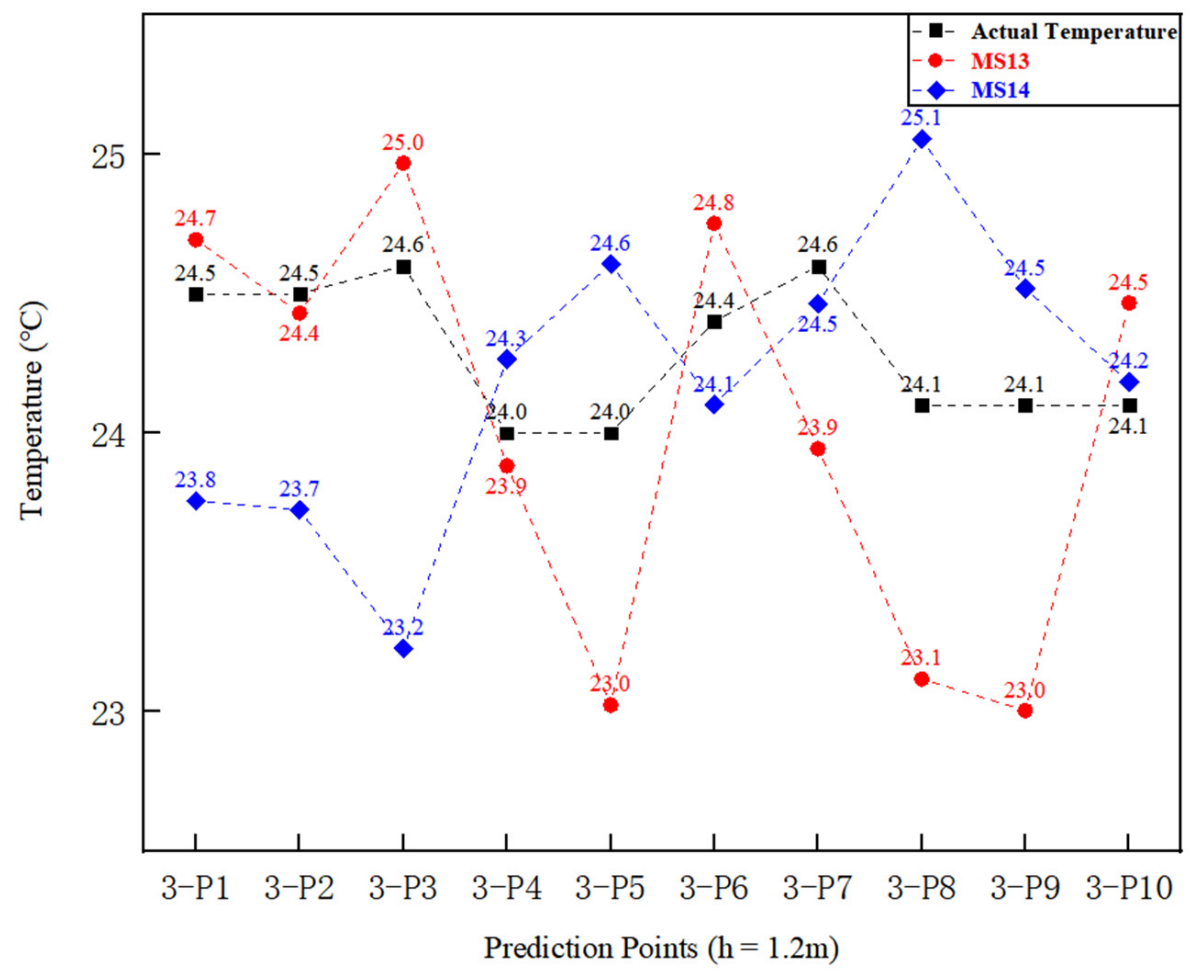

(b) Prediction results

Figure 15. Prediction of mobile sensors with acquisition distance of $5.0 \mathrm{~m}$.

Figures 11-15 and Table 4 also show the prediction results and the corresponding average relative errors of each prediction point under the various distributions of acquisition points noted above. The prediction results showed that smaller acquisition distances would make the distribution of acquisition points more concentrated, hence leading to an obvious reduction in prediction accuracy. As shown in MS1 and MS3 in Figure 11, MS7 in 
Figure 13, and MS10 in Figure 14, the corresponding average relative errors were 19.9\%, $30.7 \%, 16.7 \%$, and $9.2 \%$, respectively. However, it also had the situation that the prediction accuracy was relatively high with small acquisition distances, for example, the average relative errors were 1.6\% and 0.8\% in the cases of MS2 in Figure 11 and MS6 in Figure 12, respectively. This indicates that the uncertainty of temperature distribution prediction using the air temperature collected by mobile sensors with smaller acquisition distance was larger, and the prediction accuracy at this time cannot be guaranteed. When controlling indoor thermal environments in practical applications, it must quickly and accurately obtain temperature distributions. Therefore, it is necessary to give a design criterion for selecting an acquisition distance of mobile sensors with lower uncertainty, higher accuracy, and wider application scope. Through a careful comparison of the prediction results under the distributions of acquisition points with various acquisition distances, as shown in Figures 11-15, a conclusion was drawn that the acquisition distance should be large enough to make the distribution of acquisition points more dispersed.

Table 4. Prediction of mobile sensors with different acquisition distances.

\begin{tabular}{ccccccc}
\hline & MS1 & MS2 & MS3 & MS4 & MS5 & MS6 \\
\hline Average relative error & $19.9 \%$ & $1.6 \%$ & $30.7 \%$ & $2.7 \%$ & $2.7 \%$ & $0.8 \%$ \\
\hline & MS7 & MS8 & MS9 & MS10 & MS11 & MS12 \\
\hline Average relative error & $16.7 \%$ & $0.9 \%$ & $1.4 \%$ & $9.2 \%$ & $0.5 \%$ & $2.0 \%$ \\
\hline & MS13 & MS14 & & & & \\
\hline Average relative error & $2.1 \%$ & $2.3 \%$ & & & & \\
\hline
\end{tabular}

\section{Limitations}

Although the application of mobile sensors instead of fixed sensors to collect air temperature in the area with stable airflow distribution can greatly improve the prediction accuracy, the influence of air distribution on the method proposed in this study cannot be easily ignored. An existing study has shown that the relationship between the sensor acquisition point and the airflow direction would affect the prediction accuracy [40].

Carefully observing the acquisition point distributions in the cases of MS1 and MS3 in Figure 11, MS7 in Figure 13, and MS10 in Figure 14, it can be seen that most of them were close to wall surfaces, where the airflow distribution is relatively complex. When the mobile sensor collects the air temperature near the boundary of the room, the prediction accuracy thus cannot be guaranteed. Whereas in the case with identical acquisition distances, with acquisition points that are located in the interior of the room and far away from the boundary of the room, the prediction accuracy was improved. For example, the average relative error of the acquisition point distribution shown in MS2 in Figure 11 is 1.6\%, which is far less than the average relative error of the acquisition point distribution shown in MS1 and MS3 in Figure 11. Similarly, the comparison between the prediction results obtained under the distribution of each acquisition point shown in Figure 13 also verifies this conclusion. Therefore, to ensure the prediction accuracy, some distance between the acquisition points and the room boundaries should be given.

Additionally, the more detailed relationship between the acquisition location of mobile sensors and airflow distribution still needs to be further explored, which will be the focus of a future study. The optimization of acquisition distance and acquisition path of mobile sensors could be achieved to further reduce the time required for predicting temperature distribution in practical applications.

\section{Conclusions}

Because of the complexity and dynamic nature of indoor thermal environments and their impact on energy consumption, the control of indoor thermal environments has always been an important research focus. In this circumstance, it is necessary to obtain the 
indoor temperature distribution rapidly and in detail. In this study, a method predicting indoor temperature distribution has been proposed for the purpose of real-time prediction and precise control of indoor thermal environments in practical applications. In this method, the air temperature was collected by one mobile sensor at the working area height, and combined with the contribution ratio of indoor climate (CRI) to realize the rapid prediction of indoor temperature distribution. Through establishing a typical office room, the reliability and effectiveness of using mobile sensors instead of fixed sensors for air temperature collection for temperature distribution prediction has been verified through accuracy comparison. Furthermore, several acquisition heights and acquisition distances of mobile sensors were tested, and their impact on prediction accuracy was analyzed. The main findings from this study are summarized as follows:

(1) Due to some restrictions in practical applications, using mobile sensors instead of fixed sensors can realize the temperature distribution prediction of residential height by reducing the number of sensors. If there are no restrictions, the application of fixed sensors for prediction can also meet the requirements, but they are also limited by the acquisition height and acquisition path. Under this condition, it is possible that the combination of fixed sensors and mobile sensors can obtain higher prediction accuracy.

(2) The acquisition height of mobile sensors has shown little impact on prediction accuracy in human activity areas. By comparing the prediction accuracy of mobile sensors for temperature distribution at different heights, it was found that the difference between them was not significant. Therefore, when using mobile sensors to predict the temperature distribution in human activity areas, there is no need to specifically set the acquisition height.

(3) The acquisition distance should be large enough to make the distribution of acquisition points more dispersed. By comparing the prediction accuracy of mobile sensors with different acquisition distances, the results show that smaller acquisition distances made acquisition points more concentrated, hence reducing prediction accuracy. Considering the influence of airflow distribution, the acquisition points should be not very close to room boundaries.

From the above analysis, the method proposed in this study could be beneficial to the rapid prediction of non-uniform temperature distribution in the perspective of satisfying thermal comfort while improving energy efficiency. It will make outstanding contributions to the control strategy based on real-time response to the thermal environment.

Author Contributions: Conceptualization, W.Z. and Y.Z.; methodology, Y.Z., Z.Z. and W.Z.; validation, Z.Z.; formal analysis, Y.Z., Z.Z. and S.W.; investigation, Y.Z. and Z.Z.; resources, W.Z.; data curation, Y.Z. and Z.Z.; writing — original draft preparation, Y.Z.; writing—review and editing, Y.Z., Z.Z., W.Z., S.W. and Y.X.; visualization, Y.Z.; supervision, W.Z., S.W. and Y.X.; project administration, W.Z. and Y.X.; funding acquisition, W.Z. All authors have read and agreed to the published version of the manuscript.

Funding: This research was funded by Natural Science Foundation of China, grant number 5190080465; Special Fund of Beijing Key Laboratory of Indoor Air Quality Evaluation and Control, grant number BZ0344KF20-05; Joint Research Project of the Wind Engineering Research Center, Tokyo Polytechnic University, Mext (Japan) Promotion of Distinctive Joint Research Center Program Grant Number: JPMXP0619217840, JURC grant number 21212012.

Data Availability Statement: Not applicable.

Conflicts of Interest: The authors declare no conflict of interest. 


\section{Nomenclature}

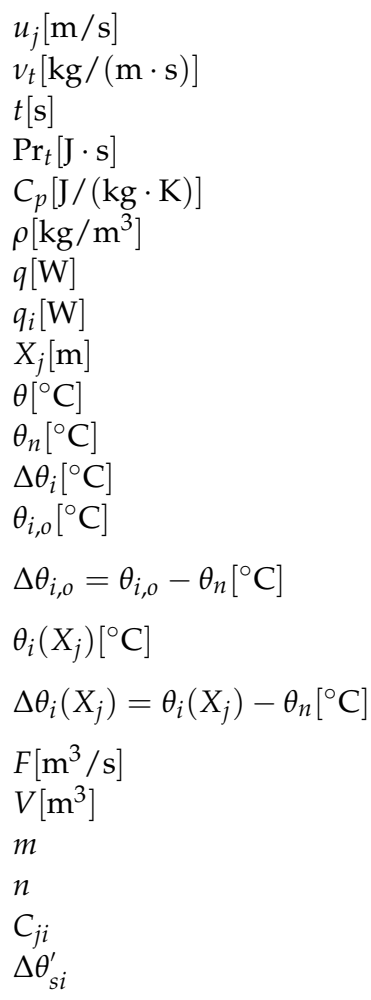

air velocity

turbulent viscosity

time

turbulent Prandtl number

specific heat of indoor air

air density

heat emission and absorption of all heat sources

heat emission or absorption of heat source $i$

component of the spatial coordinates $(j=1,2,3)$

air temperature

air neutral temperature, i.e., indoor initial air temperature

temperature rise or drop caused by heat source $i$

uniform air temperature caused by heat source $i$

temperature rise or drop of the uniform air temperature caused by heat source $i$ from $\theta_{n}$

air temperature at the location $X_{j}$ caused by heat source $i$

temperature rise or drop at the location $X_{j}$ caused by heat source

$i$ from $\theta_{n}$

volume of supply air

room volume

number of heat sources

number of sensor points

CRI of heat source $i$ to location $j$

temperature rise or drop collected by mobile sensors from $\theta_{n}$

\section{References}

1. Klepeis, N.E.; Nelson, W.C.; Ott, W.R.; Robinson, J.P.; Tsang, A.M.; Switzer, P.; Behar, J.V.; Hern, S.C.; Engelmann, W.H. The National Human Activity Pattern Survey (NHAPS): A resource for assessing exposure to environmental pollutants. J. Expo. Anal. Environ. Epidemiol. 2000, 11, 231-252. [CrossRef]

2. Liu, S.M.; Cao, Q.; Zhao, X.W.; Lu, Z.C.; Deng, Z.P.; Dong, J.K.; Lin, X.R.; Qing, K.; Zhang, W.Z.; Chen, Q.Y. Improving indoor air quality and thermal comfort in residential kitchens with a new ventilation system. Build. Environ. 2020, 180, 107016. [CrossRef]

3. Park, D.Y.; Chang, S. Effects of combined central air conditioning diffusers and window-integrated ventilation system on indoor air quality and thermal comfort in an office. Sustain. Cities Soc. 2020,61, 102292. [CrossRef]

4. Building Energy Conservation Research Centre, Tsinghua University. Annual Report on China Building Energy Efficiency; China Architecture \& Building Press: Beijing, China, 2019. (In Chinese)

5. Gilani, S.; Montazeri, H.; Blocken, B. CFD simulation of stratified indoor environment in displacement ventilation: Validation and sensitivity analysis. Build. Environ. 2016, 95, 299-313. [CrossRef]

6. Chen, C.M.; Lai, D.Y.; Chen, Q.Y. Energy analysis of three ventilation systems for a large machining plant. Energy Build 2020, 224, 110272. [CrossRef]

7. Cheng, Y.; Zhang, S.; Huan, C.; Oladokun, M.O.; Lin, Z. Optimization on fresh outdoor air ratio of air conditioning system with stratum ventilation for both targeted indoor air quality and maximal energy saving. Build. Environ. 2019, 147, 11-22. [CrossRef]

8. Zhang, S.; Lin, Z.; Ai, Z.T.; Wang, F.H.; Cheng, Y.; Huang, C. Effects of operation parameters on performances of stratum ventilation for heating mode. Build. Environ. 2019, 148, 55-66. [CrossRef]

9. Zou, Y.; Zhao, X.W.; Chen, Q.Y. Comparison of STAR-CCM+ and ANSYS Fluent for simulating indoor airflows. Build. Simul. 2018, 11, 165-174. [CrossRef]

10. Taghinia, J.; Rahman, M.; Siikonen, T. Simulation of indoor airflow with RAST and SST-SAS models: A comparative study. Build. Simul. 2015, 8, 297-306. [CrossRef]

11. Lei, L.; Zheng, H.; Wu, B.; Xue, Y. Inverse determination of multiple heat sources' release history in indoor environments. Build. Simul. 2020, 14, 1263-1275. [CrossRef]

12. Yang, X.Q.; Wang, H.D.; Su, C.X.; Wang, X.; Wang, Y. Heat transfer between occupied and unoccupied zone in large space building with floor-level side wall air-supply system. Build. Simul. 2020, 13, 1221-1233. [CrossRef]

13. Choi, H.; Kim, H.; Kim, T. Long-term simulation for predicting indoor air pollutant concentration considering pollutant distribution based on concept of CRPS index. Build. Simul. 2019, 12, 1131-1140. [CrossRef]

14. Bazdidi-Tehrani, F.; Masoumi-Verki, S.; Gholamalipour, P.; Kiamansouri, M. Large eddy simulation of pollutant dispersion in a naturally cross-ventilated model building: Comparison between sub-grid scale models. Build. Simul. 2019, 12, 921-941. [CrossRef] 
15. Sempey, A.; Inard, C.; Ghiaus, C.; Allery, C. Fast simulation of temperature distribution in air-conditioned rooms by using proper orthogonal decomposition. Build. Environ. 2009, 44, 280-289. [CrossRef]

16. Cao, S.J.; Cen, D.; Zhang, W.; Feng, Z. Study on the impacts of human walking on indoor particles dispersion using momentum theory method. Build. Environ. 2017, 126, 195-206. [CrossRef]

17. Liu, W.; Jin, M.G.; Chen, C.; You, R.Y.; Chen, Q.Y. Implementation of a fast fluid dynamics model in OpenFOAM for simulating indoor airflow. Numer. Heat Transf. Part A Appl. 2016, 69, 748-762. [CrossRef]

18. Liu, W.; Hooff, T.V.; An, Y.T.; Hu, S.; Chen, C. Modeling transient particle transport in transient indoor airflow by fast fluid dynamics with the Markov chain method. Build. Environ. 2020, 186, 107323. [CrossRef]

19. Tian, W.; Sevilla, T.A.; Zuo, W.D.; Sohn, M.D. Coupling fast fluid dynamics and multizone airflow models in Modelica Buildings library to simulate the dynamics of HVAC systems. Build. Environ. 2017, 122, 269-286. [CrossRef]

20. Liu, W.; You, R.Y.; Zhang, J.; Chen, Q.Y. Development of a fast fluid dynamics-based adjoint method for the inverse design of indoor environments. J. Build. Perform. Simul. 2017, 10, 326-343. [CrossRef]

21. Kato, S.; Murakami, S.; Kobayashi, H. New scales for assessing contribution of heat sources and sinks to temperature distributions in room by means of numerical simulation. In Proceedings of the ROOMVENT'94, Fourth International Conference on Air Distribution in Rooms, Krakow, Poland, 15-17 June 1994; pp. 539-557.

22. Sandberg, M. Ventilation effectiveness and purging flow rate-A review. In Proceedings of the International Symposium on Room Air Convection and Ventilation Effectiveness, Tokyo, Japan, 22-24 July 1992.

23. Kato, S.; Murakami, S. New ventilation efficiency scales based on spatial distribution of contaminant concentration aided by numerical simulation. ASHRAE Trans. 1988, 94, 309-330.

24. Zhang, W.R.; Kato, S.; Ishida, Y.; Hiyama, K. Calculation method of contribution ratio of indoor climate (CRI) by means of setting a uniform heat sink in natural convection air flow field. J. Environ. Eng. (Trans. AIJ) 2010, 75, 1027-1032. (In Japanese) [CrossRef]

25. Zhang, W.R.; Hiyama, K.; Kato, S.; Ishida, Y. Building energy simulation considering spatial temperature distribution for nonuniform indoor environment. Build. Environ. 2013, 63, 89-96. [CrossRef]

26. Li, X.T.; Zhao, B. Accessibility: A new concept to evaluate ventilation performance in a finite period of time. Indoor Built Environ. 2004, 13, 287-293. [CrossRef]

27. Shao, X.L.; Ma, X.J.; Li, X.T.; Liang, C. Fast prediction of non-uniform temperature distribution: A concise expression and reliability analysis. Energy Build. 2017, 141, 295-307. [CrossRef]

28. Ma, X.J.; Shao, X.L.; Li, X.T.; Lin, Y.W. An analytical expression for transient distribution of passive contaminant under steady flow field. Build. Environ. 2012, 52, 98-106. [CrossRef]

29. Cao, S.J.; Meyers, J. On the construction and use of linear low-dimensional ventilation models. Indoor Air 2012, 22, 427-441. [CrossRef]

30. Cao, S.J.; Ren, C. Ventilation control strategy using low-dimensional linear ventilation models and artificial neural network. Build. Environ. 2018, 144, 316-333. [CrossRef]

31. Ren, C.; Cao, S.J. Development and application of linear ventilation and temperature models for indoor environmental prediction and HVAC systems control. Sustain. Cities Soc. 2019, 51, 101673. [CrossRef]

32. Tian, W.; Han, X.; Zuo, W.D.; Sohn, M.D. Building energy simulation coupled with CFD for indoor environment: A critical review and recent applications. Energy Build. 2018, 165, 184-199. [CrossRef]

33. Zuo, W.D.; Chen, Q.Y. Fast and informative flow simulations in a building by using fast fluid dynamics model on graphics processing unit. Build. Environ. 2010, 45, 747-757. [CrossRef]

34. Tian, W.; Sevilla, T.A.; Zuo, W.D. A systematic evaluation of accelerating indoor airflow simulations using cross-platform parallel computing. J. Build. Perform. Simul. 2017, 10, 243-255. [CrossRef]

35. Sasamoto, T.; Kato, S.; Zhang, W.R. Control of indoor thermal environment based on concept of contribution ratio of indoor climate. Build. Simul. 2010, 3, 263-278. [CrossRef]

36. Hiyama, K.; Ishida, Y.; Kato, S. Thermal simulation: Response factor analysis using three-dimensional CFD in the simulation of air conditioning control. Build. Simul. 2010, 3, 195-203. [CrossRef]

37. Hiyama, K.; Kato, S. Integration of three-dimensional CFD results into energy simulations utilizing an advection-diffusion response factor. Energy Build. 2011, 43, 2752-2759. [CrossRef]

38. Huang, H.; Kato, S.; Hu, R.; Ishida, Y. Development of new indices to assess the contribution of moisture sources to indoor humidity and application to optimization design: Proposal of $\mathrm{CRI}(\mathrm{H})$ and a transient simulation for the prediction of indoor humidity. Build. Environ. 2011, 46, 1817-1826. [CrossRef]

39. Zhang, W.R.; Zhao, Y.N.; Xue, P.; Mizutani, K. Review and Development of the Contribution Ratio of Indoor Climate (CRI). Energy Built Environ. 2021, in press. [CrossRef]

40. Xue, Y.; Zhai, Z.Q. Inverse identification of multiple outdoor pollutant sources with a mobile sensor. Build. Simul. 2017, 10, 255-263. [CrossRef]

41. Tian, X.; Li, B.Z.; Ma, Y.X.; Liu, D.; Li, Y.C.; Cheng, Y. Experimental study of local thermal comfort and ventilation performance for mixing, displacement and stratum ventilation in an office. Sustain. Cities Soc. 2019, 50, 101630. [CrossRef] 